\title{
CUADERNOS
}

DE HISTORIA 51

DEPARTAMENTO DE CIENCIAS HISTÓRICAS

UNIVERSIDAD DE CHILE - DICIEMBRE 2019: 85-123

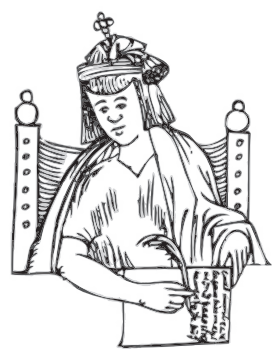

\section{CURSUS HONORUM Y CONSAGRACIÓN PROFANA: DOS LETRADOS JESUITAS EN LIMA, JOSÉ DE AGUILAR (1652-1707) Y JOSÉ DE BUENDÍA}

RESUMEN: Este articulo trata de dos destacadas figuras letradas del siglo XVII en Lima: los jesuitas José de Aguilar y José de Buendía. A través de sus éxitos como de sus reveses, se interrogan los mecanismos e instancias de promoción para los hombres de saber regulares en los virreinatos americanos, con un triple objetivo. Primero, se busca complementar una historiografía que se ha dedicado principalmente a las trayectorias de los eclesiásticos seculares o de los seglares. Segundo, se pretende resaltar el papel de la Corte para los regulares y matizar las interpretaciones que la presentan como un espacio inoperante o débil para los hombres de letras. Finalmente, el propósito es también señalar el interés para la historia intelectual de una metodología renovada en torno a los sermones.

Palabras Clave: Historia intelectual, virreinato, jesuitas, patronazgo, predicación.

CURSUS HONORUM AND PROFANE CONSECRATION: TWO JESUIT SCHOLARS IN LIMA, JOSÉ DE AGUILAR (1652-1707) AND JOSÉ DE BUENDÍA (1644-1727)

ABSTRACT: This article deals with two prominent intellectual figures of the seventeenth century in Lima: the Jesuits José de Aguilar and José de Buendia. Through their successes as well as their setbacks, the mechanisms and instances of promotion for men of knowledge regulars in the American viceroyalties are questioned with a triple objective. 
First, it seeks to complement a historiography that has been interested mainly in the trajectories of secular ecclesiastics or laymen. Second, it is intended to highlight the role of the Court for regulars and clarify the interpretations that present it as an inoperative or weak space for men of letters. Finally, the objective is also to point out the interest for the intellectual History of a renewed methodology around the sermons.

KEYWORDS: Intellectual history, Viceroyalty, Jesuits, patronage.

Recibido: 30 de octubre del 2018 Aceptado: 18 de abril de 2019

\section{Introducción}

$\mathrm{E}$ 129 de marzo de 1697, el visitador Diego Francisco de Altamirano llegó a Lima para inspeccionar la Provincia jesuita del Perú ${ }^{1}$. Dotado de poderes extraordinarios, el recién llegado provocó rápidamente una oposición interna, que se organizó como partido bajo el liderazgo del provincial titular, Diego de Eguíluz. Durante cinco años aproximadamente, los dos grupos se enfrentaron recurriendo a estrategias distintas: mientras que Altamirano y sus aliados se apoyaron en la fuerza de las prerrogativas extendidas del visitador, los partidarios de Eguíluz buscaron el respaldo de influyentes aliados externos a la orden. El 2 de diciembre de 1701, los inquisidores limeños, aliados de Eguíluz y de sus partidarios, sintetizaron indirectamente para Madrid la naturaleza de la relación de fuerza:

No representamos a V[uestra] A[ltísima] las monstruosidades, que se ven por instantes en el gobierno de este Padre visitador, la afflición de los sujetos, la opresión de los hombres más beneméritos, el desprecio de las canas, una dominación tan absoluta en gobierno tan dilatado, siendo la de visitador jurisdicción extraordinaria, y los embarazos y enquentros que tiene con el Virrey, Real Audiencia, Arzobispo y algunos obispos ${ }^{2}$.

En esta confrontación, Diego de Eguíluz se benefició desde el inicio de la adhesión de dos correligionarios destacados en la capital: José de Buendía y José de Aguilar. Desde sus respectivas posiciones, los dos hombres de letras se involucraron en la lucha contra el partido de Altamirano. Sin embargo, el

Torres Saldamando, 1882, p. 222; Vargas Ugarte, 1963, T. II, p. 319. Nacido en 1625, Altamirano era originario de Madrid. Tempranamente pasó a Paraguay.

2 Archivo Histórico Nacional [en adelante AHN], Inquisición, 4786, Exp. 3, f. 3v. 
visitador no solo poseía facultades legales extraordinarias, sino también el apoyo de las autoridades romanas de la Orden. Gracias a ello, hacia 1703, había neutralizado a sus adversarios en la Provincia y no dudó en llevar a cabo acciones punitivas, las cuales alcanzaron tanto a Buendía como a Aguilar. Pero, pese a su grado de participación similar en la lucha contra Altamirano, los dos jesuitas recibieron un trato distinto. Si bien José de Aguilar sufrió las disposiciones del visitador y varias intimidaciones, se recuperó rápidamente. De hecho, su muerte precoz en febrero de 1708, cuando se disponía a viajar a Roma como procurador de su provincia, fue lamentada por el general jesuita en persona ${ }^{3}$. En cambio, José de Buendía fue entregado al Santo Oficio y pasó los últimos quince años de su vida en un exilio forzoso en Cuzco, degradado y lejos de la capital que había celebrado su elocuencia ${ }^{4}$.

No obstante, los dos hombres de saber poseían un perfil similar en varios aspectos. Originarios de Lima, ambos nacieron alrededor de $1650^{5}$. Además de esa homogeneidad generacional, compartieron al comienzo de sus trayectorias un éxito equiparable en el ámbito limeño de la elocuencia sagrada. ¿Cómo explicar, entonces, la suerte dispar que les reservó el partido del visitador una vez concluido el conflicto que dividió la provincia? A modo de respuesta, este texto se propone demostrar que, fundamentalmente, tal fue el resultado de estrategias laborales distintas, llevadas a cabo por dos jesuitas que hicieron carrera en esferas diferentes. De manera más amplia, se trata de interrogarse aquí sobre las instancias e instituciones en las que descansaban las trayectorias de los hombres de letras regulares en una de las primeras capitales americanas del Imperio hispánico.

\section{José de Aguilar: el cursus honorum en la Provincia jesuita del Perú a finales del siglo XVII}

Más joven que José de Buendía, José de Aguilar ingresó en la Compañía de Jesús en 1666 con tan solo 14 años $^{6}$. Originario de Lima como su correligionario, el nuevo regular era de ascendencia española, en conformidad con los estatutos

"quando en el [viaje transatlántico] suelen perecer los más mozos y robustos, como lo contesta la funesta fresca noticia del P. Aguilar", Carta a José Meléndez Valdés de 23 de noviembre de 1709, Archivum Romanum Societatis Iesu [en adelante ARSI], Epp. NN, 29, f. 91v. Sobre la epístola jesuita, véase Morales 2014.

4 Medina, 1887, p. 99.

5 Salvo mención contraria, los datos sobre nacimiento y posición dentro de la Compañía de Jesús provienen de los catálogos breves o trienales de la Orden conservados en el ARSI.

6 El jesuita nació el 7 de agosto de 1652. 
de la Provincia ${ }^{7}$.Asimismo, se beneficiaba de una alta legitimidad tanto familiar como individual. A nivel familiar, estaba emparentado por parte materna con dos grandes clanes del virreinato. Procedente de Andalucía, su padre Blas de Aguilar se instaló en el virreinato para explotar las minas de Huarochirí y se casó con la criolla María de Loayza ${ }^{8}$. Por ella, Aguilar descendía por un lado de un viejo linaje de beneméritos que contaba entre sus antepasados con el primero arzobispo limeño, el dominico Gerónimo de Loayza, y su sobrino, el conquistador Alonso de Loayza (véase imagen 1) ${ }^{9}$. Por otro lado, el hombre de letras se vinculaba con los Garabito-Illescas y, a través de ellos, con su nebulosa de parientes y aliados, como los Munive o los Messia ${ }^{10}$. Para el joven jesuita, esa poderosa parentela garantizaba un amplio respaldo que, junto con su propio talento, resultaron fundamentales para su asentamiento progresivo en la Compañía. A nivel personal, el limeño tenía también la ventaja de haber nacido en un matrimonio legal, a diferencia de Buendía, quien tuvo que lidiar toda su vida con la condición de hijo natural. No obstante, la doble legitimidad del nuevo regular contrastaba con una soledad personal dolorosa, cuyo impacto es difícil de evaluar. Su madre murió durante el parto, de manera que Aguilar, además de ser hijo único, creció huérfano ${ }^{11}$.

7 Coello de la Rosa, 2008.

8 Según lo que informó el jesuita al Santo Oficio: "Blas de Aguilar fue vecino de esta ciudad [de Lima] y minero en la provincia de Guarochiri”, AHN, Inquisición, 1575, Exp. 590. Al parecer, un tío paterno de Blas de Aguilar se encontraba desde 1598 ya en el Perú. Archivo general de Indias [en adelante AGI], Contratación, 5257, N², R. 66.

9 Aguilar lo señaló a la Inquisición: "Don Gerónimo de Loayza [abuelo materno], natural de Lima a quien pusieron este nombre en memoria de Don Gerónimo de Loayza, arzobispo de esta ciudad, su tío", AHN, Inquisición, 1575, Exp. 590. Por las fechas, se trataba sin duda más de su tío abuelo. Desgraciadamente, no hemos podido determinar la rama específica del parentesco.

10 Sobre la familia Garabito-Illescas, véase, por ejemplo, Coello de la Rosa, 2008, op. cit.

11 "murió [María de Loayza] a los nueve meses de casada, del parto primero en que nació dicho Padre", AHN, Inquisición, 1575, Exp. 590. No hemos logrado averiguar si su padre se volvió a casar y si tuvo otros hijos de un segundo matrimonio. 


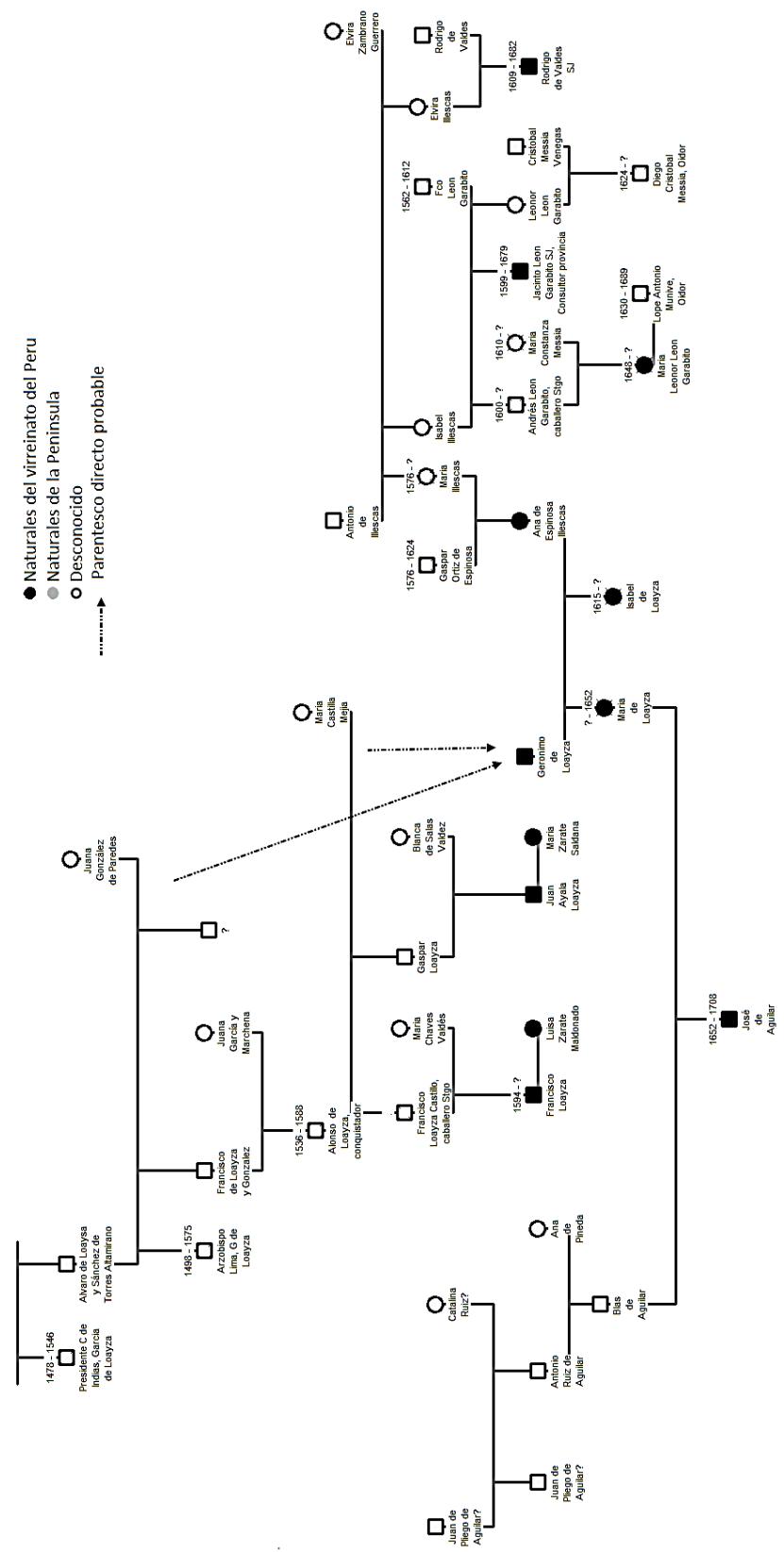

Imagen 1: Árbol genealógico parcial de José de Aguilar ${ }^{12}$

12 Elaboración propia. 
Con su entrada en la Compañía en 1666, José de Aguilar inició una exitosa trayectoria que solo interrumpiría su muerte inesperada en Panamá en 1708, a los 56 años. A diferencia de Buendía que optó por otra vía, Aguilar siguió el cursus honorum de los dignatarios ignacianos ${ }^{13}$, el cual se constituía entonces en base a dos elementos complementarios: la docencia de la teología y los cargos directivos. En una curva ascendente que no conocería la ruptura brutal de su correligionario, el limeño pasó por cuatro grandes períodos: los años formativos (1666-1677); la predicación urbana (1678-1685); la enseñanza de la teología (1686-1694); y el asentamiento institucional y erudito (1695-1708). Como etapa obligatoria, los años de aprendizaje transcurrieron favorablemente para el nuevo jesuita. Mientras cursaba los largos estudios de teología impuestos por la Orden, sus superiores lo ubicaron en el colegio del Callao, cerca de la capital. Luego, en 1678, lo regresaron a Lima, donde ocupó el primer establecimiento jesuita de la Provincia: el colegio de San Pablo. Todavía le faltaban unos años de estudios antes de los votos definitivos, pero las autoridades provinciales lo afectaron a la predicación. La afectación era bastante común, en consideración de los superiores jesuitas, se trataba de aprovechar el talento literario de los miembros jóvenes. De hecho, ya lo habían hecho unos años antes con Buendía $y$, si bien con Aguilar no dio tan buenos resultados, fue también un acierto. En el espacio de unos años, el joven jesuita llegó pues a asentarse en el campo capitalino de la elocuencia sagrada.

Como en otras partes del Imperio, en Lima dicho campo se organizaba a partir de dos elementos de importancia decreciente: el valor de los púlpitos (primera variable) y el valor de los sermones (segunda variable). En primer lugar, los púlpitos se jerarquizaban entre ellos en función de sus instituciones y sus dimensiones respectivas. En las ciudades episcopales, el púlpito de la catedral poseía, en base a resortes políticos y económicos, un prestigio mayor que el de una iglesia parroquial apartada o que el de un convento secundario aislado. En segundo lugar, los sermones se ordenaban luego según su alcance cultual, político o social. En ese sentido, una predicación para celebrar una fecha menor del calendario religioso tenía menos valor, por ejemplo, que un sermón dedicado a la Asunción o a las honras reales. De manera general, la primera variable resultaba más determinante para la configuración de los campos de la elocuencia en el Imperio. Pero, aunque fuese de menor relevancia, la segunda variable llegaba a tener en determinadas situaciones una gran incidencia. Por ejemplo, un sermón prestigioso tenía la capacidad de incrementar el valor de

13 Para trayectorias jesuitas en el XVI y comienzo del XVII, véase Maldavsky, 2012. 
un púlpito modesto ${ }^{14}$. Sobre todo, ambas variables eran fluctuantes. Mientras que la dimensión de las instituciones estaba sujeta a la elevación, al declive y a la competencia, el valor de los sermones variaba según el contexto ${ }^{15}$. En la Lima de los años de 1670, el campo de la elocuencia sagrada se constituía por diferentes polos, que dominaban la catedral y la capilla de Palacio (véase imagen 2) ${ }^{16}$. Sin coincidir plenamente con la distribución urbana de Lima, al parecer permaneció relativamente estable hasta fines del siglo, con excepción del convento de la Concepción que logró equipararse tal vez, en base a un factor demográfico, con la Encarnación durante los años de $1680^{17}$.

Si bien José de Aguilar no alcanzó la rapidez ni el grado de ascenso de Buendía, se elevó en unos pocos años en el campo limeño de la oratoria ${ }^{18}$. En 1678, año de su regreso, el joven jesuita aún predicaba para una asociación de piedad menor como la Congregación de domésticas pardas del convento de la Encarnación. El año siguiente, subió al púlpito del colegio de San Pablo, pero todavía no para su fiesta titular como Buendía en 1674, un año después de su regreso a Lima. En 1680, Aguilar prosiguió su ascenso. El 2 de abril, el hombre de letras pronunció el panegírico a Francisco de Paula en la celebración que organizaba cada año el deán Juan de Santoyo Palma. El 8 de diciembre, fue contratado para la fiesta titular de un prestigioso convento femenino, el convento de la Concepción, a la que acudieron las principales autoridades de la capital. Algunos días después, Aguilar predicó ante el arzobispo-virrey Liñán en la capilla de Palacio. Finalmente, en 1681, el orador fue consagrado por las

14 Para el campo de la oratoria de Lima, se puede mencionar el caso del sermón a San Francisco de Paula, celebrado en la parroquia de San Marcelo. Pobre, la parroquia no era muy destacada en la capital, pero gracias a la acción del deán Juan Santoyo Palma, excura de ella, la fiesta de San Francisco de Paula tomó un relieve importante. Además de costearla, el dignitario obtuvo, por ejemplo, en 1668 para la celebración la procesión anual del cabildo catedralicio.

15 Después del terremoto de 1687 , por ejemplo, ciertos sermones aumentaron su valor. Para el caso de la Nueva España y de México, la escasez de trigo y el motín de 1692 dieron una importancia especial a los sermones para San Bernardo, elevado a patrón de la ciudad en 1699 por su carácter de santo curandero.

16 Para su reconstitución, hemos cruzado criterios económicos, políticos y sociales.

17 Sus monjas pasaron de 190 en 1655 a 309 en 1688, igualando entonces al convento de la Encarnación. Fuentes, 1858, p. 467. A partir de los últimos años del siglo, nuevos conventos femeninos aparecerían que también modificarían tal vez el panorama del campo de la oratoria en la capital. Se trata del convento de las Capuchinas en 1698, del de Santa Rosa en 1704 o más tarde del de las Nazarenas en 1727. También con su elevación a Casa Profesa a comienzo del siglo XVIII, el púlpito jesuita de la Iglesia de los Desamparados adquirió mayor relieve.

18 Para la progresión de Aguilar, nos basamos en sus ocho sermonarios impresos. Si bien no constituyen la producción exhaustiva del jesuita, permiten delinear su actividad oratoria. Aguilar, 1684, 1704, 1716, 1722, 1723, 1731. 
más altas instancias. El 30 de mayo de 1681, subió al púlpito de la catedral para pronunciar el panegírico al rey San Fernando, recientemente impuesto por Carlos II. Seis meses más tarde, el 7 de diciembre de 1681, sus superiores lo escogieron para dar un sermón de orden protocolar, celebrado diplomáticamente cada año en el convento dominico como señal de amistad. Para fines de 1681, Aguilar se inscribía pues en el campo de la oratoria de manera tanto céntrica como plural, lo cual representaba un éxito para un joven clérigo de 29 años que aún no había concluido sus estudios.

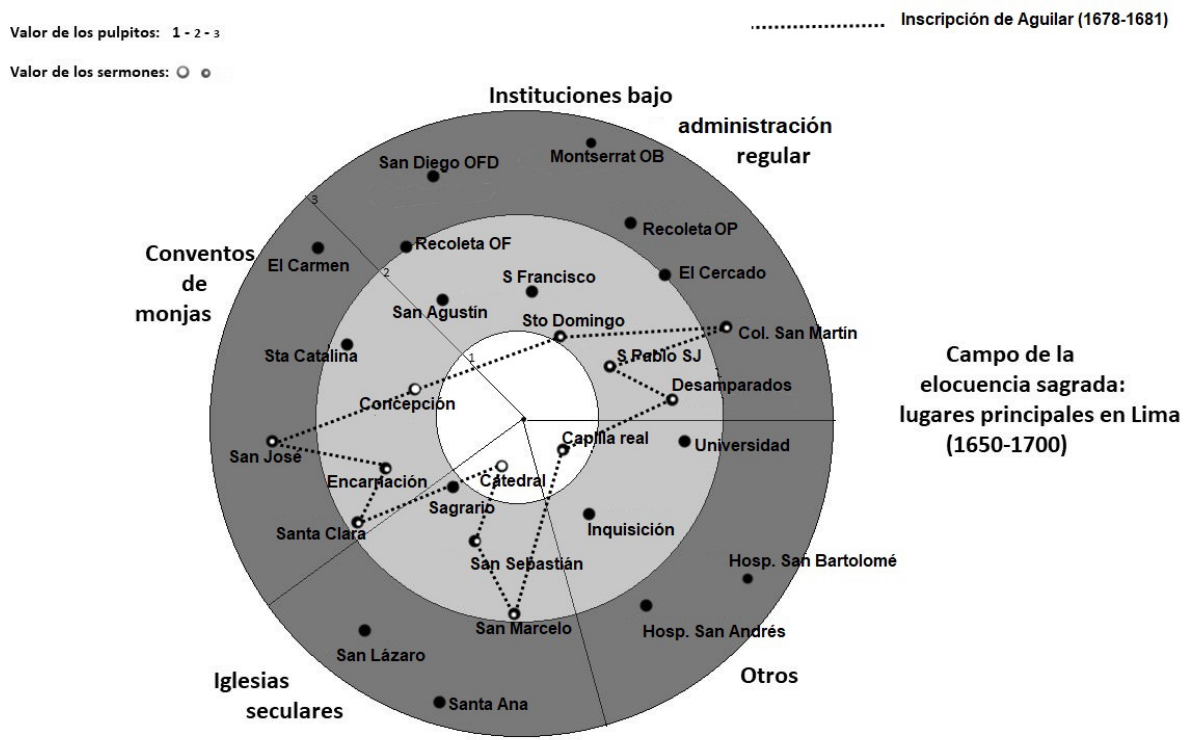

Imagen 2: Progresión inicial de José de Aguilar en el campo de la oratoria (1678-1681) ${ }^{19}$

Para los predicadores en el Imperio, la elevación en los diferentes campos de la elocuencia dependía de diversas variables, que combinadas o no, actuaban como fuerzas ascendentes (protecciones poderosas, marco profesional... ${ }^{20}$ ). La progresión de Aguilar en el campo de la elocuencia descansó en dos factores complementarios: el auditorio y el clan. Por una parte, el favor del público constituyó una primera fuerza impulsora, pues la receptividad a los sermones

19 Elaboración propia. Hemos cruzado datos políticos, sociales y económicos, sin embargo, la imagen no tiene pretensión de exhaustividad.

20 En el Imperio, el mercado laboral para los eclesiásticos seculares no favorecía, por ejemplo, un desempeño fuerte de su parte en la predicación. Pues su primer empleador, el Estado real, privilegiaba otros criterios para el reclutamiento. Cf. Aguirre, 2003. 
del clérigo elevó su cotización como orador y aumentó el número de sus solicitaciones. Pero, a diferencia de Buendía que se benefició inmediatamente de una más amplia audiencia, el público no permitió por si solo el asentamiento de Aguilar. De hecho, en 1678, sus superiores notaron que la elocuencia del joven jesuita no era equiparable a la de su correligionario ${ }^{21}$. La complejidad de su fórmula sermonaria limitaba pues el margen de adhesión de los feligreses. A nivel estilístico, Aguilar se suscribía a un lenguaje austero. Sobre todo, en términos de género, se inscribía en una predicación intelectualista, de orden conceptista, que dominaba entonces la escuela de predicación jesuita y que él llevó hasta un alto grado de sofisticación. Su gusto por el enigma textual y su resolución lo empujaron a la acumulación de argumentaciones complejas, por las cuales Vargas Ugarte llegó a calificarlo de "en ocasiones frio y falta de sentimiento" 22 .

Dicha limitación fue compensada por la fuerza de su clan, que representó el segundo factor de elevación para el orador en el campo de la oratoria. Dentro de la Provincia, Aguilar poseía múltiples apoyos destacados, entre los cuales se encontraban los dignatarios Jacinto de León Garavito y Rodrigo de Valdés, ambos primos de su abuela Ana de Espinosa Illescas (véase imagen 1). De ejercer como rector del colegio San Pablo, el primero pasó en 1678 a integrar la junta directiva de la provincia como consultor provincial. Desde esta posición de poder, León Garavito podía usar su influencia para imponer, directa o indirectamente, a su joven pariente para dar sermones de la Orden. En 1678, su otro familiar, Rodrigo de Valdés, era por su parte prefecto de la Congregación de la $\mathrm{O}$, una prestigiosa asociación de piedad jesuita para los eclesiásticos. Fue allí precisamente, donde José de Aguilar pronunció un sermón ante el arzobispo-virrey, en diciembre de 1679. En la esfera profana, el hombre de letras también contaba con protectores influyentes. Dos primos suyos, Lope Antonio Munive y Diego Cristóbal Messia ejercían como oidores. Hasta entonces asentado en Lima, el primero fue promovido en enero de 1678 a la presidencia de la Audiencia de Quito, a donde se mudó rápidamente. El segundo en cambio permaneció en Lima y pudo beneficiar a su pariente ${ }^{23}$. En 1696, José de Aguilar

21 Cuando el catálogo secreto de 1678 calificaba la predicación de Buendía de óptima ("ad concionan optimum"), la de Aguilar era tachada de mediocre ("ad concionan mediocre"). Catálogo secreto de 1678, ARSI, Perú 5.

22 Según Vargas Ugarte: “Aguilar tomó por maestro a Antonio de Vieyra”, Vargas Ugarte, 1942, p. 37. También: "me parece en ocasiones frio y falta de sentimiento [...], razona más que siente, convence más que emociona". Vargas Ugarte, 1942, op. cit., p. 41.

23 Sobre Messia y su desempeño clientelar y arraigo limeño, véase de la Puente Brunke, 1990, p. 344. 
señalaría como el oidor "[le] obligó a predicar [sermones]" y le expresaría su gratitud $^{24}$. Para la parentela del jesuita, se trataba tanto de apoyar la joven carrera de uno de los suyos en nombre de la solidaridad familiar como de alimentar el prestigio del linaje a través de la figura de un orador estrella.

De hecho, ese primer apoyo activo del clan no quedó sin compensación. Tal como lo haría en otras ocasiones, el hombre de letras ofreció parte de su éxito como contrapartida a sus parientes ${ }^{25}$. En 1684, Aguilar puso pues su primera producción impresa al servicio de un esfuerzo de justificación de un poderoso y cercano aliado de su linaje: el exvirrey Conde de Castellar. Durante su gobierno, Castellar se había asociado con Munive y Messia, a quienes concedió sucesivamente la administración de Huancavelica y de su estratégico azogue ${ }^{26}$. Depuesto por el Estado monárquico en julio de 1678, el Conde se enfrentó a múltiples acusaciones ${ }^{27}$. En dicho contexto, el primer sermonario de Aguilar sirvió de tribuna para el antiguo aliado de sus primos. Dirigida a Castellar en persona, la dedicatoria de la publicación defendió el balance del virrey caído:

Todo él [el Perú] grita, que en V. Ex. [el Conde de Castellar] reconoció, como en su centro, la justicia, el zelo de la honra de ambas Magestades, la prudencia en los sucesos, la infatigable asistencia a los despachos. [...] Esto vocea todo aquella Corte del Perú, y aunque valiéndose de las distancias, [h]aya procurado apagar estas voces la calumnia, como son voces de la verdad, son muy altas y es preciso que se oigan... ${ }^{28}$.

Un año después, en 1685, Aguilar ya constituía una figura destacada en el campo de la oratoria sagrada en la capital gracias a su fórmula sermonaria y al

24 Aguilar, 1704, T. III. Aguilar dedicó a Messia su tercer sermonario y concluyó su dedicatoria con: "Reciba pues, V. S., esta corta expresión de mi gratitud.", Ibid., [f. 14v]. El sermonario se publicó en 1704, pero el jesuita firmó la dedicatoria el 20 de julio de 1696. Además de esa dedicatoria, Aguilar mencionó el papel de patrocinador de Messia en varios de sus sermones. Véase, por ejemplo, Aguilar, 1704, T. II, p.38; T. III, p. 352.

25 El uso de Aguilar de la dedicatoria merecería un examen más detenido. El jesuita repartió sus dedicatorias entre sus proyectos con la Compañía, de orden mayoritariamente teológico (Aguilar, 1701, T. I; T. II), y su solidaridad familiar con sus sermonarios (Aguilar, 1684; 1704). A su muerte, fue su primo Andrés Munive Garabito quien recuperó precisamente el proyecto de publicación de sus sermones (Aguilar, 1715; 1716...). La parte teológica fue recuperada en cambio por el jesuita José Pérez Ugarte (Aguilar, 1731).

26 Por ser centro de producción de azogue en América, Huancavelica era particularmente importante. A una fecha desconocida, Castellar había asistido también a un acto de teología de Aguilar: Aguilar, 1704, T. I, [f.1v].

27 Sobre las razones de la destitución de Castellar, véase Suarez, 2015.

28 Aguilar, 1684, [f. 2v]. véase passim también. 
apoyo de los suyos. Sin embargo, al concluir el mismo año los largos estudios jesuitas, el orador decidió apartarse de la predicación para dedicarse a otro ministerio: la enseñanza de la teología. Por entonces, esta constituía la actividad suprema entre las diversas actividades ignacianas y, sobre todo, era la puerta de entrada al grupo de dignatarios jesuitas tanto en el Perú como en las demás provincias. En teoría, representaba la consumación del ideal intelectualista de la Orden. En 1700, el visitador Altamirano señaló al respecto que "[solo como discípulos] no la pueden saber toda [la teología] ni aprenden comúnmente más que las materias que les dictan; [...] sabiduría que no se aumenta, y perfectiona hasta que la obligación de la Cátedra los sublima" ${ }^{29}$. En la práctica, fue para las instancias romanas un criterio sistemático para seleccionar a los provinciales y a los principales rectores. A nivel local, el resto de los cargos de poder también tendía a distribuirse entre los antiguos lectores teólogos.

Con apenas diez cátedras para más de 100 profesos, la integración al cuerpo de teólogos docentes era no obstante bastante restringida en la Provincia peruana ${ }^{30}$. Asimismo, debido a su impacto sobre las trayectorias, dicho sector sufría una alta presión que generaba rivalidades y frustraciones. A nivel institucional, se procuró regularlo a través de un sistema de ascenso gradual y una rotación frecuente. Primero, los profesores debían trabajar en los colegios de La Plata o del Cuzco antes de pretender ocupar una de las cuatro cátedras de teología del colegio de San Pablo ${ }^{31}$. Segundo, a diferencia de las cátedras universitarias, los docentes se turnaban las cátedras a los pocos años con el fin de compensar su número restringido con una disponibilidad más alta ${ }^{32}$. Sin embargo, en las últimas décadas del siglo, ese sistema había llegado a sus límites. Por su valor, las codiciadas cátedras estaban incluidas en los mecanismos de clientelismo dentro de la Orden y constituían retribuciones a las lealtades y alianzas. Fue debido a esta situación que el visitador Altamirano obtuvo, apenas llegado a Lima, la fidelidad del ariqueño Luis de Andrade. De la misma edad que Aguilar, Andrade fue apartado de la docencia teológica hasta 1696. En cambio, Aguilar

29 AHN, Inquisición, 4786, Exp. 3, f. 35v.

30 En 1685, el San Pablo de Lima contaba con cuatro cátedras de teología, el colegio cuzqueño y el de La Paz con tres cátedras cada uno. Cf. Memoria de los ministerios [...] de esta Provincia del Perú, ARSI, Perú 11. En 1654, la Provincia contaba con 150 profesos de 4to vto., en 1672 con 111, en 1681 con 101 y en 1690 con 122. Esa situación hizo señalar en 1701 a dos dignitarios: "el no leer [teología] en la Compañía [en su Provincia peruana] los que llegan al grado de profesos, es defecto accidental, pues nace de [...] no aver cátedras para tantos", AHN, Inquisición, 4786, Exp. 3, f. 50r.

31 En la Congregación Provincial de 1692, se solicitó la suspensión de este sistema. Cf. Vargas Ugarte, 1963, op. cit., p. 309.

32 Las cátedras tendían a turnarse cada trienio. 
podía contar otra vez con la influencia e intervención de su retícula de familiares y aliados. Pues cuando en 1685 terminó sus estudios, el socio del Provincial, Nicolás de Olea, era un pariente cercano de su primo y oidor Diego Messia ${ }^{33}$.

A corto plazo, el traslado a la docencia de la teología implicó variados sacrificios para el hombre de letras. Primero, supuso su salida de la capital virreinal hacia una ciudad de menos importancia política: La Plata. Segundo, significó también un periodo alejado del colegio San Pablo para desempeñarse en un colegio de menor rango: el colegio San Juan Bautista. En torno al año 1660, el jesuita Cristóbal Merinero criticó precisamente el exceso de atractivo del colegio limeño en comparación con el del Cuzco, por ejemplo. Entonces rector cusqueño, Merinero pidió al Provincial que "Aya justa repartición de los sugetos, no se queden allá [en el San Pablo] todos los buenos y acá vengan los malos y achacosos" ${ }^{\prime 34}$. Tercero, para Aguilar implicó sustraerse al régimen de reconocimiento de la predicación, cuyas manifestaciones eran rápidas y elevadas, para supeditarse a un régimen más lento y menos brillante.

No obstante, a mediano plazo y en términos de trayectoria, los beneficios de dicho cambio rebasaron ampliamente sus costos iniciales. Con su traslado, Aguilar se suscribía a los valores más legítimos de su institución a diferencia de Buendía, que se adhirió a instancias externas a la Orden. Una vez integrado al cuerpo de profesores de teología, el hombre de letras pudo empezar a elevarse en su jerarquía interna y a acumular diversas responsabilidades y cargos prestigiosos, apoyado nuevamente por el poderío du su clan. En 1690, a los 38 años, obtuvo su primer cargo de gobierno con el rectorado del colegio Real de San Juan Bautista, en La Plata. En 1695, el jesuita reintegró Lima ya no como simple operario, sino para ocupar la cotizada cátedra de víspera de teología del San Pablo. Cuatro años más tarde, en 1699, la Congregación provincial lo designó procurador para Roma ${ }^{35}$. El año siguiente, Aguilar fue promovido al

33 Sobre su parentesco, véase Aguilar, 1704 [f. 5v].

34 Carta del Padre Merinero al Provincial, [sin fecha], ARSI, Perú 21 a, f107r. También: "Embiense también PP Espirituales a este colegio, q con sus canas, exemplo autoridad y consejo, los repriman, edifiquen y vaian de la mano y a buen seguro que no aya tantos escándalos. Es muy bueno que S Pablo se tenga toda la autoridad madurez consejo y canas de la provincia, i que quieran al Cusco tan sin escandalosos como a S Pablo. Miresse y abendase al Cusco con el amor y afecto q a Lima, pues es miembro tan principal de esta provincia tan hijo de Sn Ignacio y de la Compañía de Jss como S Pablo parte noble y muy noble deste cuerpo, q con esso no todo lo bueno se quedara en el S Pablo sino que se repartirá y repartido será de salud y de virtud para todo este cuerpo místico y religioso, el qual anduviera compuestissimo en sus acciones y no se descompondrá en tanto escándalo", Idem. Sobre el desempeño educativo ignaciano en el Cuzco, véase también, Rodríguez Garrido, 2017.

35 Sin flota disponible, el viaje se vio finalmente anulado. 
rectorado del tercer colegio de la Compañía en la capital después del San Pablo y del noviciado: el colegio Real de San Martín. Para 1700, esa acumulación de cargos constituía un logro profesional para el jesuita. Aguilar sobrepasaba por entonces ampliamente en el organigrama de la Provincia a Buendía, quien evolucionaba por su parte en la informalidad de la Corte. Además, ya se acercaba a los criterios de selección de la sede romana, la cual, en paralelo a la docencia teológica, consideraba la experiencia gubernamental para sus nombramientos a los cargos directivos más altos.

De manera correlativa, el ascenso de Aguilar en la jerarquía jesuita provocó, apenas regresó a Lima en 1695, su reconocimiento por diversas instancias de poder. En 1696, el Santo Oficio lo integró como calificador ${ }^{36}$. En una fecha desconocida, el prelado Melchor de Liñán y Cisneros lo nombró examinador sinodal del arzobispado ${ }^{37}$. Incluso la Corte de Monclova empezó a manifestar consideración por el hombre de letras. A finales de 1695, Aguilar fue invitado a la Capilla de Palacio para su primer sermón desde su regreso a Lima ${ }^{38}$. A diferencia de José de Buendía, que evolucionaba entonces cerca del virrey bajo un régimen cortesano, el orador fue convidado por su autoridad moral. Frente a su auditorio, no dudó en pronunciar un discurso incisivo que rompía con el tenor de sus predicaciones de los años 1678-1685. Para el jesuita:

Mirad [jueces] que no es vuestra la justicia, sino de quien la tiene, y puede ser que la tenga el estraño; vuestro es el dar la sentencia; pero no es vuestra el darla a favor de los vuestros, sino de los que tuvieron en su favor las leyes; vuestro es hazer justicia, pero no es vuestro el darla... ${ }^{39}$.

Influyendo de manera centrípeta, la nueva dimensión de Aguilar y su condición de dignatario reconfiguraron incluso su posición dentro del campo de la elocuencia sagrada en Lima. De 1695 en adelante, su inscripción se estrechó aún más a su centro. A partir de su regreso a Lima, cuando el jesuita abandonaba puntualmente la docencia por la predicación, solo subía a escenarios prestigiosos para sermones destacados (véanse imagen 3 y 4). Entre 1695 y 1706, sus púlpitos fueron casi exclusivamente los de la catedral, de Palacio y de la

36 AHN, Inquisición, 1575, Exp. 590.

37 Desgraciadamente, ignoramos la fecha del nombramiento.

38 Según Aguilar: "empiezo oy después de unos algunos años, que me retiró a otros exercicios, y tierras la obediencia, $[. .$.$] mas empezar en lugar tan supremo, y en tan respetoso concurso...".$ Aguilar, 1704, p. 114.

39 Aguilar, 1704, p. 132. Compárese en especial con el sermón antecedente del tomo, que es para una ocasión similar 15 años antes. El tono es irreconocible. 
Inquisición ${ }^{40}$. Aguilar ya solo se desplazaba además para dar sermones de un alcance político o cultual relevante. A nivel político, sus sermones en la Capilla de Palacio o en la Inquisición tenían un alto interés. En la catedral, pronunció en 1700 y 1704 sermones vinculados con la autoridad regia: las honras a los soldados de la monarquía. A nivel del culto, Aguilar tendió a especializarse en un género eminente de sermón mariano: la concepción inmaculada. Tema central del culto a la Virgen, era prestigioso para los oradores porque consistía en parte en un ejercicio teológico, a diferencia de panegíricos más clásicos. Era además un tipo de sermón particularmente concurrido en el Imperio. En diciembre de 1662 en Lima, la reticencia de los dominicos en reconocer el carácter inmaculado de la virgen había producido desbordes populares ${ }^{41}$.

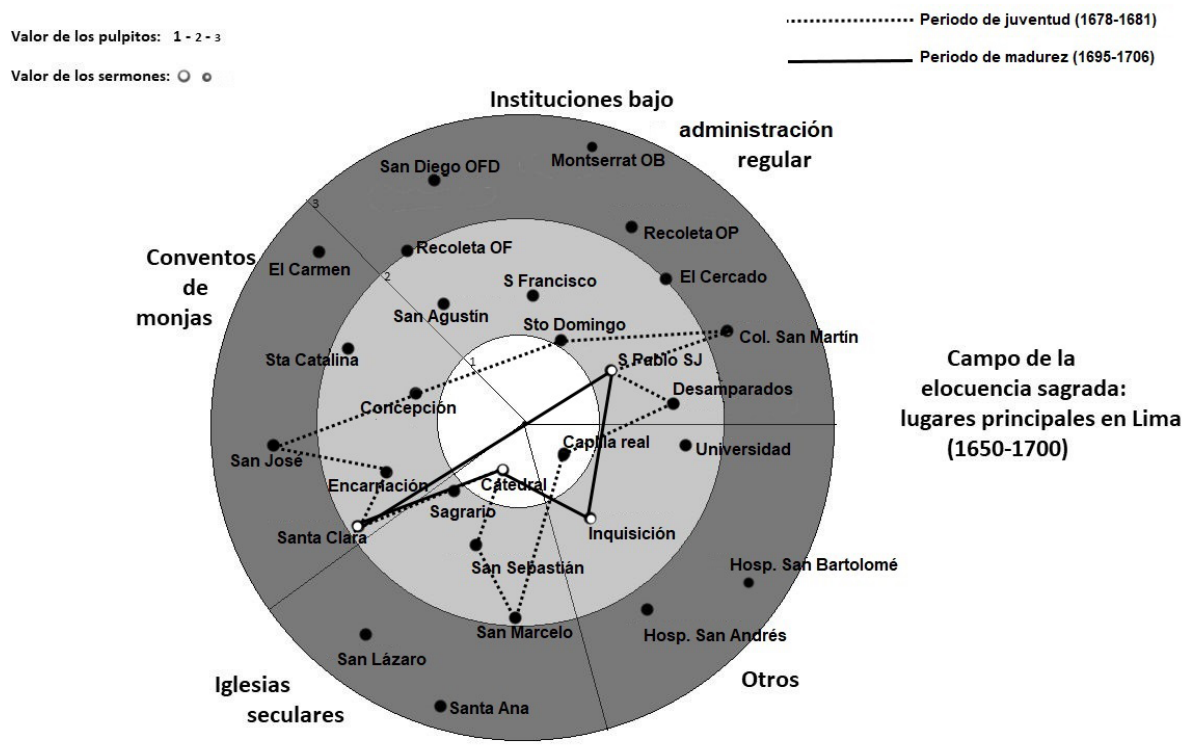

Imagen 3: Concentración de la actividad oratoria de JDA en el centro del campo (1695-1708) ${ }^{42}$.

40 Según los sermones publicados e identificables, durante este período predicó solo una vez al Convento de Santa Clara, en 1697, y una al San Pablo, en 1698. Sus demás predicaciones fueron en los tres espacios mencionados.

${ }^{41}$ Mugaburu, 1918, T. I., pp. 85-86.

42 Elaboración propia. 

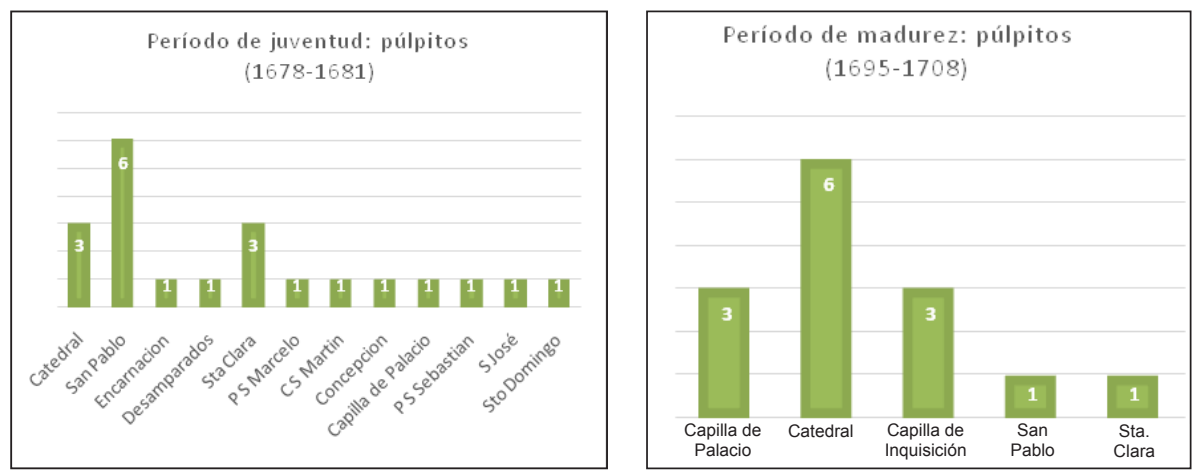

Imagen 4: Reducción cualitativa de los espacios de intervención de José de Aguilar ${ }^{43}$

Hacia 1700, mientras Buendía evolucionaba en los medios cortesanos y se beneficiaba del favor profano, José de Aguilar era pues integrado al aparato dirigente de su Orden y poseía un nivel elevado de reconocimiento de parte de instancias legítimas externas. Este fuerte arraigo institucional representaba la consecuencia lógica de su supeditación a los primeros valores de la Compañía y de la fuerza de sus protecciones familiares. De hecho, cuando estalló el conflicto que sacudió a la provincia entre1697 y 1702, aproximadamente, aquello fue lo que le permitió atravesar el episodio sin demasiados percances.

Las tensiones se iniciaron en marzo de 1697, en torno a la figura del visitador Diego Francisco de Altamirano ${ }^{44}$. Originario de Madrid, el recién llegado era encargado por Roma de inspeccionar la Provincia peruana después de haber llevado con éxito la visita de la del Nuevo Reino. Pero si bien había cumplido sin problema con su misión en Quito, en Lima se atrajo rápidamente la enemistad de poderosos dignatarios en la Provincia, quienes se sintieron desplazados por la política del visitador. Desde finales de la década de 1680, la Provincia se encontraba dominada por una facción de jesuitas que tendían a repartir entre sus allegados los principales cargos de la institución. En su cúspide, reunía personalidades como las del Provincial titular, Diego de Eguíluz, el consultor de la Provincia, Hernando Tardío, o el rector del San Pablo, Francisco Xavier Grijalva $^{45}$. Como Buendía, José de Aguilar era parte de esa agrupación por razones tanto internas como externas a la Compañía. Por ejemplo, Tardío era

43 Elaboración propia en base a los sermones predicados y localizados de Aguilar.

44 El conflicto será examinado detalladamente en otro trabajo.

45 Véanse los jesuitas que se presentan en la Inquisición para apoyar a Eguíluz en contra de Altamirano: AHN, Inquisición, 4786, Exp. 3, f. 5v. 
amigo de su primo Diego Messia ${ }^{46}$. Como parte de su empresa, Altamirano trató de disolver ese grupo con el apoyo de algunos marginados y descontentos, entre los cuales estaban Luis de Andrade y Joaquim de Velasco. De ese modo, se constituyeron dos partidos en la Provincia, que se enfrentaron durante algunos años, hasta que el visitador logró acallar a sus opositores.

En tanto que partidario de Eguíluz, Aguilar no dudó en participar varias veces en maniobras destinadas a desestabilizar al grupo enemigo ${ }^{47}$. Su principal actuación se dio a finales de junio de 1700. El día 26, el partido de Eguíluz aprovechó la gira de inspección del visitador en el virreinato para tenderle una trampa ${ }^{48}$. En la mañana, el jesuita Francisco Xavier de Zalduendo se presentó ante los inquisidores para declinar el cargo de calificador que se le ofrecía, aduciendo que Altamirano había impuesto la necesidad de su acuerdo previo en el cuaderno de la visita del colegio de San Pablo. Naturalmente, para los funcionarios del Santo Oficio constituía una vulneración de su autonomía institucional. En cambio, para los adversarios del visitador se trataba en cambio de desencadenar en su contra el poder inquisitorial en Lima. En el transcurso del mes de septiembre, los inquisidores mandaron una carta a Altamirano que se encontraba en Potosí para pedirle la abrogación de su directiva. El jesuita les contestó el primero de noviembre asegurándoles que se plegaba a sus consideraciones. No obstante, con la intención de verificar la pertinencia de su respuesta, los inquisidores solicitaron, el 18 de enero de 1701, la opinión de dos de sus calificadores: Eguíluz y Aguilar. Como era de esperar, ambos emitieron un dictamen negativo sobre la carta de su adversario. Según ellos, "no satisfacía d[i]cho Padre Visitador, con muchas otras razones, que dedujeron, fundándose en las mismas Leyes, que la Compañía de Jesús tiene"49. Con base en sus pareceres, el fiscal del Santo Oficio llegó a requerir pues la convocación de Altamirano para que "fuesse grave y severamente reprehendido por el grave exceso que avia cometido" ${ }^{50}$.

Gracias a sus hombres en Lima, el visitador estaba bien informado de las intrigas de sus adversarios. Para devolver el golpe, destituyó unos meses después a un partidario de Eguíluz, Francisco Xavier Grijalba, entonces rector

46 Tardío mencionó a la Inquisición que Messia lo visitaba en su celda. AHN, Inquisición, 4786, Exp. 3, f. 74r.

47 Aguilar se opuso, por ejemplo, al visitador sobre la cuestión de las becas del San Martin en 1700. Pastells 1912: T. V, 14. Sobre el episodio, véase también Colección Vargas Ugarte, T. 14, doc. 47-50.

48 Sobre el episodio, véase Guibovich Pérez, 2003, pp. 78-80.

49 AHN, Inquisición, 4786, Exp. 3, f. 5v.

50 AHN, Inquisición, 4786, Exp. 3, f. 6r. 
del San Pablo, que había transmitido a los inquisidores, justo después de la comparecencia de Salduendo, el cuaderno que lo incriminaba ${ }^{51}$. Determinado a impedir la destitución de uno de los suyos, el bando de Eguíluz se movilizó rápidamente. Llamaron a la opinión pública limeña y, de nuevo, a la Inquisición. El 15 de abril de 1701, Eguíluz acudió a su tribunal para señalar que la decisión de Altamirano solo era motivada por "odio del Santo Oficio" 52 . El 18 de abril, apenas tres días después que su jefe, José de Aguilar se presentó a su vez en la sede inquisitorial para confirmar sus alegaciones. Según él, "debe impedir [la Inquisición] su execución [la despedida de Grijalba]"53. De hecho, el trámite logró desestabilizar por un tiempo al visitador, quien tuvo que renunciar temporalmente al traslado de Grijalba. Sin embargo, gracias a sus prerrogativas extendidas y al apoyo de Roma, Altamirano retomó en 1702 el control de la Provincia y no dudó en desquitarse con sus adversarios caídos ${ }^{54}$.

El visitador quitó a Eguíluz, que no era Provincial desde 1698, su cargo de consultor de la Provincia ${ }^{55}$. Sobre todo, hacia 1703, lo rebajó al cargo de simple operario en el San Pablo. Un partidario suyo, Mateo de Orellana, cayó del directorio de la Provincia a la prefectura de una pobre asociación de piedad: la congregación de los pardos del San Pablo. Como Buendía, José de Aguilar también fue incluido en la operación de represalias. Sin embargo, en relación con su grado de implicación y en comparación con otros, el hombre de saber fue relativamente preservado. Con base en sus facultades, en noviembre de 1701, Altamirano le quitó el rectorado del San Martin, donde Aguilar apenas habría estado un año, para regresarlo al San $\mathrm{Pablo}^{56}$. No obstante, el hombre de letras recuperó un cargo prestigioso en el colegio: la cátedra de Vísperas de

51 "era un castigo conocido, solo porque había conocido y denunciado en el Santo Oficio la ordenación", AHN, Inquisición, 4786, Exp. 3, f. 8v.

52 AHN, Inquisición, 4786, Exp. 3, f. 8r. Sobre la opinión pública, véase: “de lo notorio que era en la Ciudad [el odio de Altamirano al Santo Oficio]", Idem; "a qué se añadía estar divulgado en esta Ciudad, así de la primera graduación como el Virrey, Arzobispo, Real audiencia, y demás vecinos", Ibid., f. 10r; "se ha esparcido por toda ella [la Republica] y bulgarizado en esta Corte, de que se había hecho público el casso", Ibid., f. 11r.

53 AHN, Inquisición, 4786, Exp.3, f. 69v.

54 Altamirano era amigo del General Tirso de González, con quien trabajó en España. Aguilar [1716], 5, 21.

55 En 1700, Altamirano se lo quitó por haberse expresado "con alguna falta de moderación". Vargas Ugarte, 1963, op. cit., p. 323.

56 La duración normal en el rectorado del San Martin era de varios años. Los sucesores de Aguilar, Juan de Valdespina y Bartolome de Larrea, se quedaron un trienio. Cf. Anales martinianos del colegio jesuita de San Martín de Lima, AHN, Códices, L.241, f. 12v. Para el cargo de Aguilar en el San Pablo, véase Catálogo breve de 1703, ARSI, Lima 11. 
teología. En 1704, cuando el visitador ya ocupaba el rectorado del San Pablo, Aguilar pudo ascender incluso a la prefectura de los estudios superiores del colegio. El puesto constituía la antesala de importantes cargos de gobierno que habían ocupado dignitarios, ex profesores de teología, como Rodrigo de Valdés o el propio Eguíluz antes de llegar a provincial. En paralelo, si bien el visitador manifestó alguna desconsideración hacia Aguilar ${ }^{57}$, su equipo en el poder continuó atribuyéndole apreciaciones favorables ${ }^{58}$. En 1706, el hombre de saber incluso fue designado nuevamente como procurador de la Provincia para Roma ${ }^{59}$. Poco después de su muerte, el 26 de febrero de 1708, durante la escala en Panamá, el General en persona lamentó su desaparición en una carta para José Meléndez Valdés, nuevo capitular del cabildo catedralicio limeño ${ }^{60}$.

¿Cómo explicar la resistencia de Aguilar a los ajustes de cuentas internos a la Orden? A diferencia de Buendía, el hombre de letras era protegido de las represalias del visitador por la calidad de su asentamiento institucional, tanto desde una perspectiva estructural como coyuntural. En términos estructurales, su arraigo jerárquico le proporcionó una protección estatutaria en la Orden. Las constituciones de la compañía reglamentaban las sanciones contra sus miembros e imponían su gradación en función de las posiciones. Mientras más elevados se encontraban los miembros en la cadena de mando, más difícil era coaccionarlos. Dichas constituciones obligaban, por ejemplo, a pasar por el arbitraje romano, lo cual tampoco convenía a Altamirano. Asimismo, la afiliación del jesuita a dos instituciones como el arzobispado y la Inquisición constituyó otra sólida protección estructural. En términos coyunturales, la sólida posición institucional de Aguilar también lo favoreció. Primero, Altamirano ya había castigado a los dignatarios más visibles que estuvieron implicados en las insubordinaciones en la Provincia, como Eguíluz y Grijalva, por lo cual no podía permitirse escarmentar a muchos más. De hecho, otro partidario de Eguíluz, Fernando Tardío, también logró sortear las degradaciones debido a su condición de alto directivo. Segundo, en el contexto del reciente enfrentamiento entre Altamirano y los inquisidores, estos no habrían dudado en defender vehementemente a Aguilar en tanto que calificador de su institución.

57 Según los Inquisidores: "los calificadores de quienes más [...] nos valemos, y en otro tiempo se veían honrados de sus Provinciales, [h] oy se ven intimidados", AHN, Inquisición, 4786, Exp. 3, f. 3r.

58 Para 1700: "jucio suficiente, prudencia ídem". Para 1706: "juicio bueno, prudencia buena". Catálogo secreto de 1700, ARSI, Lima 6.

59 Sobre la importancia clave del papel de procurador, véase Fechner, 2014.

${ }^{60}$ ARSI, Epp. NN., 29, f. 91v. 
En síntesis, además de su talento y de sus propios méritos, José de Aguilar logró su posición profesional gracias a dos elementos. Por un lado, siguió la lógica de la Compañía y pasó por las diferentes etapas que esta imponía (la docencia teológica y cargos cada vez más prestigiosos). Por otro lado, en este proceso, Aguilar contó con el apoyo activo de su poderoso clan, que le ayudó en múltiples ocasiones.

\section{José de Buendía: una estrategia fundada sobre la consagración profana}

Nacido en 1644 en la arquidiócesis limeña, José de Buendía ingresó a la Compañía de Jesús siete años antes que Aguilar, con 15 años, el 23 de enero de $1659^{61}$. $\mathrm{Al}$ igual que su correligionario, el nuevo clérigo regular era de ascendencia española. Sin embargo, Buendía se diferenciaba de Aguilar tanto en términos familiares como individuales. A nivel familiar, el jesuita carecía de la calidad de su arraigo social. Según Torres Saldamando ${ }^{62}$, Buendía provenía de la rama segunda de un pequeño linaje criollo de influencia política limitada y cuya base social se encontraba en Huancavelica (véase imagen 5). Hacia 1608, su abuelo, Juan de Buendía, se instaló en el virreinato como veedor de minas, con su esposa y su hijo mayor Agustín ${ }^{63}$. Casado con la hija del escribano de Indias Cristóbal de Cuellar ${ }^{64}$, fue Agustín quien heredó y prolongó directamente el desempeño paterno en el azogue huancavelicano ${ }^{65}$. José de Buendía Corchado, su hermano menor y padre del jesuita, tuvo en cambio una envergadura más modesta. Aunque obtuvo el cargo de Alguacil perpetuo del Tribunal de la Cruzada, en 1644, Buendía Corchado se casó más sencillamente con la limeña

${ }^{61}$ Sobre la trayectoria de Buendía, véase también Millar Carvacho, 2018, pp. 570-572.

62 Las informaciones dadas por Torres Saldamando han de tomarse no obstante con una doble precaución. Primero, el historiador no menciona sus fuentes y pudo haber sido víctima de un homónimo. Segundo, del matrimonio Buendía-Pastrana nació de manera tardía, el 13 de diciembre de 1664 en Huancavelica, otro hijo llamado José García. La familia Buendía-Pastrana contaría entonces con dos José.

63 Juan de Buendía se registró en noviembre de 1607 en la Casa de la Contratación, con su mujer María Sánchez Corchado y su hijo Agustín. AGI, Contratación, 5298, N.2, R.47. Hijo del ensayador y visitador general de las minas de Castilla Agustín de Buendía Balcazar, Juan de Buendía realizó una labor importante en Huancavelica.

${ }^{64}$ La boda se realizó el 14 de junio de 1646. Cuellar obtuvo el cargo en 1612 y falleció en enero de 1656. AGI, Lima, 181, N.24.

${ }_{65}$ Como minero solicitó y obtuvo en 1650 una encomienda en Huancavelica. AGI, Lima, 201, N. 29. 
María de Pastrana ${ }^{66}$. Salvo el hombre de letras jesuita, sus primeros hijos tuvieron también trayectorias medianas ${ }^{67}$. Habría que esperar hasta inicios del siglo siguiente, con el jesuita ya bien establecido, para que la rama menor de los Buendía llegase a prosperar ${ }^{68}$.

66 En 1650, compró el título por 12000 pesos. Cf. Benito Rodríguez, 2000, pp. 169-190.

67 Bautizada el 23 de mayo de 1645, Josefa de Buendía Pastrana entró en 1654 en el Convento de la Encarnación donde probablemente terminó tomando el velo. Por su parte, su hermano Juan de Buendía Pastrana siguió la carrera de las letras. En septiembre de 1684, casó con Juana de Villafuerte.

68 Gracias al último hijo del matrimonio Buendía-Pastrana, que nació tardíamente, en 1664: Lohmann Villena, 1993, T. II, p. 290. Este último embarazo resultó tal vez fatal a María de Pastrana, quien testó pocos meses después de dar a luz, el 15 de agosto de 1665. 


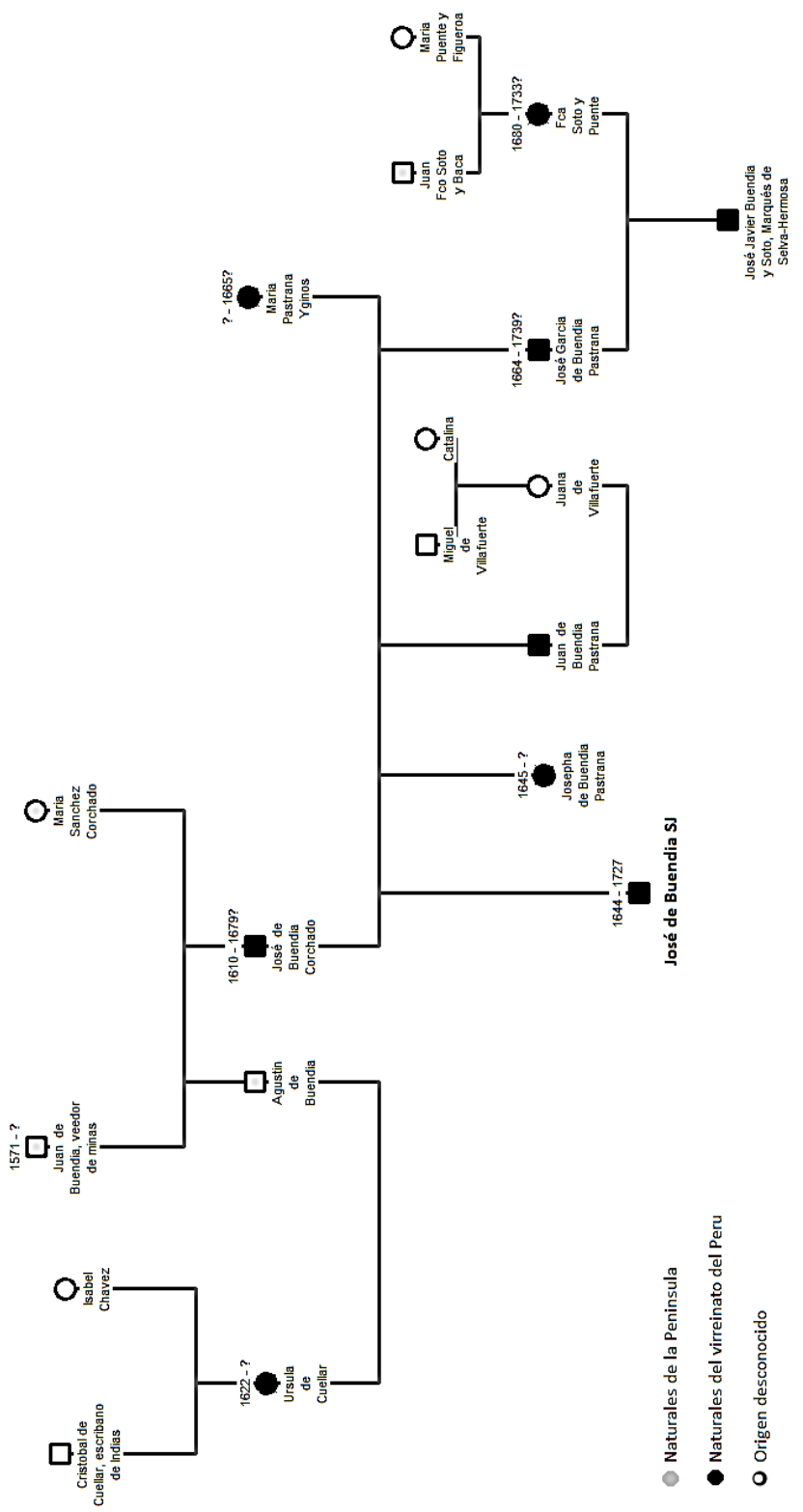

Imagen 5: Orígenes familiares de José de Buendía

(Una rama secundaria de un pequeño linaje criollo) ${ }^{69}$

69 Elaboración propia. 
Paralelamente a su origen familiar mediano, el joven jesuita presentaba a nivel personal otra característica inicial significativa, cuyo impacto es difícil de evaluar. Si el hombre de saber fue hijo de José de Buendía y de María de Pastrana, su nacimiento se dio fuera de matrimonio. Según las informaciones reiteradas por su Orden, el jesuita nació el 21 de enero de 1644. No obstante, la boda de sus padres se celebró en Lima cuatro meses después, el 5 de mayo de $1644^{70}$. De una manera u otra, dicha condición de hijo natural constituyó una marca negativa para José de Buendía. De hecho, unos 40 años más tarde, en abril de 1701 y abril de 1703, cuando se presentaría ante los Inquisidores, el jesuita se cuidaría de ocultarla, aplazando la fecha de su nacimiento en algunos años ${ }^{71}$.

Cuando en 1659 ingresó a la Orden, se abrió para José de Buendía un largo período de más de 60 años, cuya duración se extendió hasta su muerte en mayo de 1727. Basándose en una estrategia diferente a la de Aguilar, la trayectoria del hombre de saber se articuló también en cuatro grandes fases: los años de formación (1659-1672); la primera celebridad (1673-1689); la consagración cortesana (1690-1705); y la caída (1705-1727). Las dos primeras fases fueron similares a las de Aguilar. Al igual que su correligionario, José de Buendía tuvo una escolaridad exitosa. Destacó rápidamente sobre sus compañeros, de tal manera que se convirtió en la figura principal de su promoción ${ }^{72}$. Para 1666, a los 21 años, las autoridades provinciales subrayaron tanto sus habilidades literarias como sus cualidades para el conjunto de los ministerios en la Orden ${ }^{73}$. Luego, al igual que Aguilar más tarde, el hombre de saber se vio colocado primero en el colegio del Callao. En 1673, regresó también en Lima, al colegio de San Pablo, donde inició su segunda etapa en la Compañía. Con ello, inauguró lo que sería una larga fase de su trayectoria, la cual descansó mayoritariamente en el favor de una esfera profana y externa a la institución: el público urbano.

Del mismo modo que Aguilar, sus superiores enviaron al joven jesuita al ministerio de la predicación antes de terminar sus estudios. No obstante, en

70 Lohmann Villena, 1993, T. II, op. cit., p. 291.

71 En abril de 1701 afirmó tener 49 años. AHN, Inquisición, 4786, Exp.3, f. 80v. Luego, en abril de 1703, retrasó su nacimiento a 1646.AHN, Inquisición, 648, Exp.20, f. 16v. Es probable que Buendía no hiciera más que repetir ante los inquisidores una estrategia que empleaba ante otros. De hecho, a nivel de la Compañía misma, la ilegitimidad constituía también una mancha, pues el 27 de febrero de 1694, el general Tirso de González la equiparaba al mestizaje como condición negativa. Cf. Vargas Ugarte, 1963, op. cit., T. II, p. 305.

72 Eran 9 novicios en total: Blaso Ochoa, Juan de Montes, Christobal Vargas, Cosme Ygarza, Juan Guerra, Felipe Alvicuri, Hernando Colmenero, José Robles.

73 "literatura: bonus, [...] talentos: Ad omnia satisfacione", Catálogo secreto de 1666, ARSI, Perú 5. 
comparación con su correligionario, la decisión funcionó más rápidamente. En dos años, Buendía conquistó el campo de la elocuencia sagrada en la capital ${ }^{74}$. Apenas regresó del Callao, José de Buendía predicó tres veces en su primer púlpito, la catedral, en presencia del arzobispo en persona. Si bien era un buen comienzo, no se trataba todavía de grandes sermones. Pese a ello, Buendía prosiguió su progresión durante los meses posteriores y, ya en julio y agosto, logró aparecer en circunstancias más significativas. Por un lado, fue contratado por los conventos de la Trinidad y de las Carmelitas para sus fiestas titulares, a las que asistieron las principales autoridades de la capital. Por otro lado, el 15 de agosto de 1673, sus superiores le encargaron el panegírico a Estanislao Kostka, con motivo de su celebración en el San Pablo. Finalmente, a finales de 1673, el hombre de saber regresó a la catedral para una ocasión esta vez más importante, las encenias. Durante el año de 1674, José de Buendía continuó su ascenso. Además de regresar nuevamente a la catedral, sus jefes lo escogieron para pronunciar el panegírico a San Pablo del Colegio de San Pablo, el 30 de julio de dicho año. Para la Provincia jesuita, el evento era muy prestigioso. Se trataba de la fiesta oficial del primer establecimiento de la Orden en el virreinato, el cual hospedaba al Provincial y a su equipo, y el orador hacía de representante oficial. A menos de dos años de su regreso, José de Buendía se inscribía, como Aguilar más tarde, en el campo capitalino de la oratoria de modo céntrico y plural. Para su joven trayectoria, significaba un primer éxito.

74 Nos basamos en el sermonario anónimo Sermones varios predicados en la ciudad de Lima del Reyno de Perú, publicado en Zaragoza en 1678. A partir de Saldamando, la autoría del sermonario ha sido atribuido a menudo a Martin de Jáuregui. Sin embargo, varios elementos contradicen esta atribución en favor de Buendía. Primero, los argumentos de Eugenio Uriarte. Uriarte informa la tesis de Saldamando basándose en el sevillano Ambrosio de la Cuesta y Saavedra y señala que el propio Saldamando cambió dos veces de opinión. Segundo, los catálogos de la Provincia. Entre 1673 y 1675, Jauregui no se encontraba en Lima sino en el Callao como rector de su colegio. En cambio, Buendía sí se encontraba en Lima como operario. La mudanza de opinión de Saldamando se explica tal vez por la desgracia final de Buendía y su deseo de preservar la imagen de la Compañía. Uriarte, 1905, T. II, pp. 184-185. 


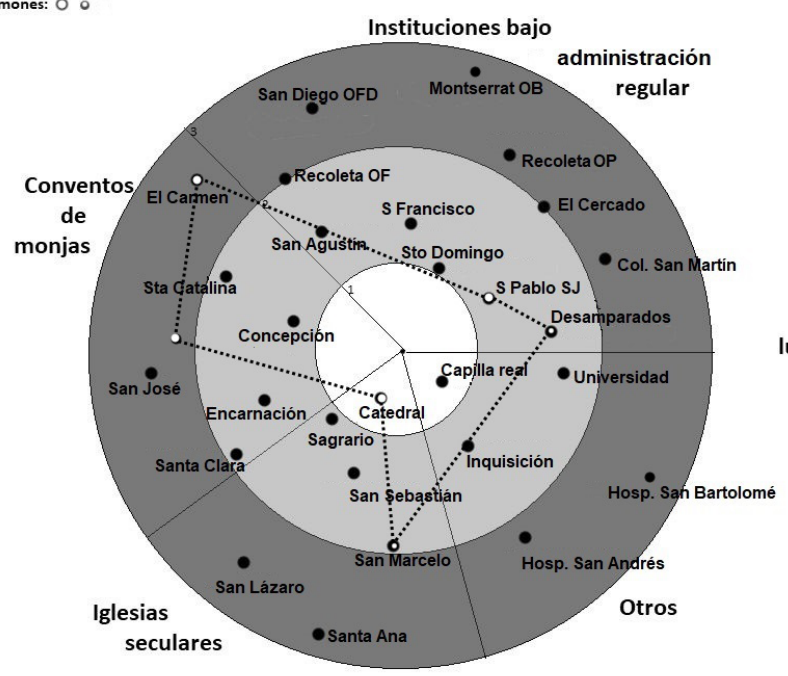

Campo de la elocuencia sagrada: lugares principales en Lima (1650-1700)

Imagen 6: Inscripción cualitativa de José de Buendía en el campo limeño de la oratoria durante sus primeros años como predicador $(1673-1674)^{75}$

Así como el ascenso de Aguilar en el campo de la oratoria se debió a la conjunción de dos fuerzas, la progresión acelerada de Buendía se basó principalmente en un solo factor: la adhesión inmediata del público urbano a su fórmula sermonaria. Hacia 1670, el joven limeño empleaba una elocuencia diferente de la que estaba entonces de moda entre los jesuitas: más florida y emocional. Por una parte, se inclinaba hacia un discurso sofisticado que Coello califica incluso de cultista ${ }^{76}$. En efecto, sin llegar a ser oscuro, Buendía cultivaba una fuerte vertiente estética, fundada en un trabajo fino de las figuras estilísticas, a diferencia de Aguilar quien utilizó siempre un lenguaje sobrio. Por otra parte, el hombre de saber cuidaba el impacto afectivo de su discurso, por ejemplo, empleando frecuentemente la apóstrofe. En 1680, esta perspectiva emocional de su elocuencia le hizo preguntar a una feligresa "si avia llorado [al oir sus sermones]" lo distinguió de la predicación conceptista que reinaba entonces sobre la escuela de predicación jesuita y a la que se suscribió su correligionario. ¿Cómo explicar esta especificidad oratoria del joven jesuita a sus inicios? ¿Se trataba, a nivel

77 AHN, Inquisición, 1648, Exp. 20, f. 5r. 
individual, de una preferencia personal o de una estrategia de distinción? ¿Era consecuencia, a nivel institucional, de la persistencia de un cultismo vulgarizado en la Provincia? Sea como fuere, Buendía suscitó mucha expectación entre los fieles en la capital. Más accesible, pero al mismo tiempo elaborada, su fórmula sermonaria sedujo a un amplio público urbano, aficionado a las formas elegantes y sensibles, que se movilizaba numeroso para escucharlo ${ }^{78}$.

Como en del resto del Imperio, para los oradores el favor urbano seguía en Lima a los canales de la popularidad y del renombre. Hacia 1675, el éxito de José de Buendía se caracterizaba por dos aspectos: una celebridad urbana (auge simbólico) y una envergadura relacional inédita (auge social) ante sectores seglares. No solo el joven jesuita era por entonces famoso en Lima, sino también se hacía próximo a diferentes redes de fieles influyentes, quienes contribuyeron incluso a introducirlo más adelante en la Corte. Pero frente a esta consagración de orden mundano y profano, Buendía manifestó sin embargo de fachada una cierta distancia. Para sus superiores como para los sectores eruditos, el público urbano no constituía en efecto una instancia legítima. En la lógica de la intelectualidad limeña, la práctica de la predicación era incluso subordinada a una actividad apartada de las multitudes y de su juicio: la docencia. Cuando tuvo la oportunidad, Buendía tendió a ostentar su adhesión a esa lógica erudita. Para su primera publicación, en 1676, uno de sus censores, el dominico Cypriano de Herrera, presentó al jesuita tanto como maestro y orador, pese a la dimensión de sus éxitos en los púlpitos de la catedral y al carácter menor de su actividad de docente ${ }^{79}$. Bajo su pluma, la primera instancia de consagración del jesuita pasó incluso artificialmente del público urbano a un cuerpo profesoral erudito. Según Herrera: "en el teatro de los estudios deste Reyno tantos doctos insignes le celebran [a Buendía]"

En Lima, el proceder no era inédito. Al contrario, numerosos eran los oradores que tendían también a reivindicar un desempeño educativo en sus

78 Para el alto grado de éxito de Buendía y su celebridad, nos basamos en los comentarios sistemáticos de sus pares, los cuales constituyen los indicios más accesibles en términos de fuentes primarias respecto a la recepción de los sermones. Por ejemplo: "cada día aplaudimos en los Pulpitos desta Corte", Buendía, 1676, [f. 1r]; "antorcha del amor divino en la predicación, venera hoy Lima en la grande Compañía de Jesús, siendo entre todos el primogénito su Autor", 1693a, [f. 6v]; "en tumultuarios concursos han logrado tan veces el beneficio de sus vozes en los pulpitos y en las plazas de Lima", 1693b, [27r]; "la destreza tan conocida como aplaudida", 1701, [f. 4r] ...

79 "[es] lo escrito tan docto, como todo lo demás, que ha enseñado en la Catedra el Autor, y cada día aplaudimos en los pulpitos desta Corte", [Buendía], 1676, [f.1r].

80 Ibid. 
publicaciones, así fuese cierto o $\mathrm{no}^{81}$. De hecho, Buendía reiteró varias veces su gesto. En la práctica, el jesuita se adhirió no obstante a la lógica de la esfera seglar que lo consagraba. Pese a sus demostraciones de conformidad erudita, cultivó activamente su actividad oratoria y se suscribió a la apreciación del público urbano, el cual funcionó para él como una instancia de referencia central. En dicha primacía dada a los sectores profanos y a sus criterios reside pues la diferencia central entre Buendía y Aguilar. El primero adoptó una estrategia laboral basada en el público, mientras que el segundo siempre se subordinó en prioridad a la lógica institucional de su Orden.

En lugar de cambiarse a otros ministerios como ocurrió con Aguilar, José de Buendía escogió permanecer principalmente en el apostolado urbano en la capital. En 1678, el limeño tenía casi terminados sus estudios y sus superiores seguían distinguiendo sus cualidades literarias y competencias pedagógicas ${ }^{82}$. Ciertamente, tanto el final de los estudios como esa doble evaluación positiva le ofrecían la posibilidad de un traslado interno de la elocuencia sagrada a la enseñanza de la teología, lo cual le hubiese permitido acceder al grupo de los dignatarios jesuitas y a los cargos de mayor rango en la Orden. Sin embargo, pese al valor del ejercicio, José de Buendía siempre prefirió permanecer en Lima como predicador. Para el hombre de letras, no se trataba de una elección secundaria. Al contrario, Buendía manifestó constantemente hacia la elocuencia sagrada una verdadera adhesión y un orgullo profesional. En 1680, se relacionó con una feligresa en base al argumento de su excelencia oratoria ${ }^{83}$. En marzo de 1694, no dudó en citarse a sí mismo, en una aprobación para otro predicador, para subrayar la fuerza de una sus propias figuras retóricas: "discurría yo, aver

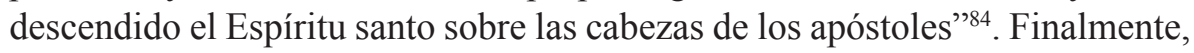
el 11 de abril de 1703, cuando se disponía a autodenunciar por actos de solicitante, José de Buendía afirmó al inquisidor Gómez Suarez de Figueroa que su gestión era motivada en parte por sus propias predicaciones. Según el jesuita, su elocuencia lo había autoconvertido:

81 Es el caso, por ejemplo, de Aguilar también. Véase su primera publicación de sermones: "No ha tenido por exercicio el predicar, fino el leer Gramática: ministerio en que aquella Santa Provincia del Perú ocupa a sus mayores sugetos los primeros años de fu Sacerdocio", Aguilar, 1684, [f. 4v].

82 "literatura: bonus, [...] talento: [...] ad legendy bonum", catálogo secreto de 1678, ARSI, Perú 5. El 2 febrero 1679, Buendía hizo su profesión de $4^{\circ}$ voto, la cual ratificaba los estudios.

83 Según una denuncia por solicitante, Buendía se presentó preguntando: "as oydo mis sermones [...], volvió a preguntar que si avia llorado”, AHN, Inquisición, 1648, Exp. 20, f. 5r.

${ }^{84}$ Vargas Machuca, 1694, [f. 7v]. El proceder es sumamente inusual. 
y aseguro a V[uestra] S[enoria] debajo del mismo juramento que no [h]e procedido a esta denunciación por noticia que [h] aya tenido de que me [h]ayan de denunciar; sino por recelo originado del caso que llevo dicho, y porque el $\mathrm{S}[\mathrm{en}]$ or cuya passion santísima [h] e predicado me [h] a inspirado a que me denuncie, y s[an]to Francisco Xavier cuya novena he predicado ${ }^{85}$

Esta permanencia de Buendía en el campo de la predicación descansó obviamente en el favor de la esfera profana, a la que se esforzaba en cultivar activamente. Además de mantener una fórmula retórica seductora, el jesuita se dedicó, a partir de 1676, a responder a sus preferencias espirituales, las cuales regían una temporalidad de la actualidad y de la moda. A mitad del año, el hombre de letras se enfrascó en una devoción en boga en Lima: las lágrimas de un cuadro de la Virgen de la Iglesia jesuita del Callao. Se habían manifestado apenas nueve meses antes, el 29 de septiembre de 1675, y dieron luz a un fenómeno de piedad colectiva tanto más amplio cuanto que se trataba de la primera manifestación de este tipo en la capital y sus alrededores. Según manifestó el propio Buendía, inmediatamente la Corte y "muchos [de la Ciudad de Lima] han ido como en peregrinación a visitar la Santa Imagen, llevándole flores y luces"86. En Lima misma, "crece cada día más el concurso y amor de el Pueblo"87. Probablemente hacia el mes de mayo, cuando la devoción seguía vigente en los sectores profanos y mundanos, el jesuita pronunció, según su estilo acostumbrado, un sermón en su honor ${ }^{88}$.

De hecho, la prestación de Buendía tuvo tan buena acogida por parte del auditorio que le permitió incluso una incursión en librería algunos meses después. Probablemente pensando en el cumpleaños del llanto mariano, volvió a trabajar su sermón para convertirlo en un relato con Sudor y lágrimas de Maria Santissima en su Santa Imagen de la Misericordia ${ }^{89}$. De manera similar a la predicación original, el texto iba destinado a un amplio público, tal como

85 AHN, Inquisición, 1648, Exp. 20, 16r.

86 Los virreyes, el arzobispo y la nobleza de la ciudad han ido al Callao: "siguiendo tan soberanos exemplares muchos Señores, así de la Real Audiencia, como del Tribunal de la Santa Inquisición, Cruzada y otros caballeros", [Buendía], 1676, f. 9v.

87 [Buendía] 1676, f. 9v.

88 Sudor y lágrimas es en parte la adaptación de un sermón de Buendía. Pues Pedro de Cárdenas y Arbieto, segundo censor, señaló: "leí gustoso lo que días â escuche admirado" [Buendía], 1676, [f. 5r]. La obra se publicó sin nombre de autor en la portada, mas en la primera aprobación del agustino Herrera se indicó al autor, Buendía. [Buendía], 1676, [f. 1r].

89 La licencia de publicación más tardía es del 3 de julio de 1676, por lo cual calculamos una llegada a las librerías por el mes de agosto. 
lo señaló uno de sus comentaristas ${ }^{90}$. En su reescritura, Buendía descartó el modelo erudito del relato hagiográfico para suscribir doblemente a un formato de vulgarización. Por una parte, rechazó la prolijidad erudita. Para el hombre de letras, se trataba de una relación y no de un libro, lo cual lo llevó a dejar de lado el aparato crítico en beneficio de una inteligibilidad más grande ${ }^{91}$. Por otra parte, Buendía conservó el estilo elegante y claro de la producción oratoria. Bajo su pluma, las lágrimas de la Virgen

parecieron perlas del más fino oriente, y en el esplendor diamantes de mucho fondo, reverberando a la reflección de la luz como pudieran, las estrellas en el cielo, o como una vía láctea ${ }^{92}$.

Un año más tarde, a finales de 1677, el hombre de letras se sumó a otro episodio de fervor colectivo de moda. En la mañana del domingo 7 de noviembre, el seglar Nicolás de Ayllón falleció en su casa ${ }^{93}$. Su muerte produjo de inmediato en Lima importantes demostraciones de piedad que implicaron, de la misma manera que las lágrimas de la Virgen, una diversidad de sectores profanos ${ }^{94}$. Tanto la población urbana como poderosos grupos cortesanos participaron en las diversas ceremonias de homenaje ${ }^{95}$. Las honras del difunto fueron incluso organizadas por la Real Audiencia, el 15 de noviembre, en la Iglesia dieguina, la cual se vio rápidamente saturada por la multitud ${ }^{96}$. Para participar de la emoción colectiva, José de Buendía obtuvo pronunciar el elogio fúnebre a Ayllón, de quien había sido el último director espiritual. En el centro de las festividades,

90 "utilidad y conveniencias espirituales para todos", [Buendía], 1676, [f. 1r].

91 Por ejemplo: "otros muchos efectos experimentados ya no se cuentan por no crecer a libro, lo que nació relación” [Buendía], 1676, f. 11v.

92 [Buendía], 1676: f. 5r. Véase también: "enjuga compasivo y amante los tiernos ojos de los justos, al beber el rocio de las niñas llorosas de su Madre se le carera de la mano la espada de su rigor, arrebatado de su hermosura" [Buendía], 1676, f. 2r.

93 Véase sobre el tema: Espinoza Rúa, 2012. Como factor de desarrollo de la santidad, Espinoza Rúa señala el papel de la burocracia inquisitorial. Con Buendía se podría añadir la ambición individual de un personal eclesiástico. También: Estenssoro Fuchs, 2003.

94 Para el entierro, por ejemplo, el 10 de noviembre: "Numeroso gentío acudió a su entierro, de tal modo que fue necesario que los soldados de la guardia del Virrey fuesen a casa del difunto y a la Iglesia, a fin de poder trasladar el cadáver e impedir los atropellos de la multitud", Vargas Ugarte, 1960, op. cit., p. 75.

95 "Fue un espectáculo verdaderamente digno de admiración [...] ver en ese día [de la muerte de Ayllón] lo más lustroso y estimable del mundo: El Sacerdocio, la Nobleza, las dignidades, los Habitos, las varas de los Jueces y las Togas de los Senadores...", Vargas Ugarte, 1960, op. cit., pp. 73-74. El virrey Castellar y su familia se implicaron también mucho. El Marqués de Rivas, sobrino de la virreina, ayudó incluso a cargar el cuerpo. Sartolo, 1684, p. 217.

96 Sartolo, 1684, pp. 220-221. 
se empeñó en producir un sermón que gustase a su auditorio urbano. Como lo reconoció algunos días antes, el jesuita estaba plenamente consciente del gusto por la novedad de sus oyentes ${ }^{97}$. Para satisfacer sus expectativas, José de Buendía no dudó entonces en franquear la reserva debida a su estado de clérigo, atribuyendo al difunto milagros no corroborados en un discurso que quería original. De hecho, sus superiores le reprocharían algunos días después esas concesiones a las preferencias del público ${ }^{98}$. La Inquisición misma, unos veinte años más tarde, se lo haría pagar.

¿Cómo explicar esta suscripción del hombre de letras a una vía que sin embargo lo alejaba del cursus honorum de su Orden y, aún con mayor amplitud, de los criterios de valorización de la esfera erudita limeña? Diferentes factores pudieron combinarse. Primero, dependió tal vez de consideraciones propiamente laborales por parte de Buendía, quien estimó en su situación la elocuencia sagrada más conveniente (factor profesional). De manera general, la estrategia de orden institucionalista, seguida por Aguilar, implicaba un ascenso progresivo y austero. Asimismo, la docencia de la teología, que constituía un requisito ineludible, era un sector además muy presionado entre 1680 y 1690 , debido a su impacto sobre las trayectorias y al escaso número de cátedras, lo que favorecía los fenómenos clientelistas. En términos comparativos, la predicación ofrecía una consagración rápida, muy ostensible y menos peleada. Para un orador como Buendía, talentoso pero carente de altos apoyos, representaba pues una alternativa atractiva. Segundo, el jesuita también pudo apostar por la sociabilidad que ofrecían los púlpitos y que no favorecían la docencia ni las aulas (factor social). En efecto, la celebridad de los oradores constituía un elemento atractivo para los poderosos círculos seglares en el Imperio. Por su origen mediano y su condición de hijo natural, Buendía estimó que tal vez eran más interesantes los beneficios de una alta sociabilidad seglar que los del entorno erudito y estudiantil. De cualquier manera, hacia finales de la década de 1680, esa estrategia laboral era un éxito para José de Buendía. Con 45 años, no solo se había construido una verdadera autoridad en la esfera urbana, sino también frecuentaba importantes clanes seglares, como el del santiaguista Echave y Assu ${ }^{99}$.

97 Algunos días antes del sermón, Buendía le preguntó a la esposa de Ayllón: "Si sabes María algunos milagros deste siervo de Dios, dímelos para que [h]agamos algún sermón y los publiquemos; [...], porque ya saves la novedad de Lima que son noveleros", AHN, Inquisición, 1648, Exp. 20, f. 24v.

98 “a mí, mi prelado me ha reñido, que para qué prediqué aquel sermon”, Ibid., f. $25 \mathrm{v}$.

99 Echave y Assu publicó en 1688 su Estrella de Lima, actualizando sin duda algunos detalles. En 1693, a través de su amigo franciscano Como, Buendía reveló su autoría. Buendía, 1693, [f. 26r]. 
A nivel de la Provincia, sus superiores consideraron posiblemente útil para la influencia de la Compañía en Lima mantener en sus filas a un orador bien relacionado y apreciado por los feligreses. Sin embargo, no ratificaron sus éxitos con lo que constituía la primera gratificación en la institución: el ascenso. Al contrario, Buendía se estancó en la jerarquía interna en un simple puesto de operario. Es más, aunque reconocían su excelencia oratoria, las evaluaciones de las autoridades jesuitas para Roma eran particularmente mediocres para el orador estrella. Por ejemplo, en 1690, el catálogo secreto señaló la debilidad de su juicio y de su prudencia ${ }^{100}$. De hecho, este estancamiento interno en un puesto básico constituiría en el mediano plazo una deficiencia para Buendía y una ventaja para sus adversarios en la Provincia. A nivel de la intelectualidad limeña, el desfase entre la consagración profana y la apreciación de los pares era similar. En 1685, el mercedario Francisco de Velasco reconoció, en un contexto no obstante adverso, que Buendía era un "religioso de autoridad" 101 . Pero el jesuita era tomado en consideración por su gran visibilidad como predicador más que por algún magisterio erudito o espiritual. Semejante situación se veía además acentuada por la aparición de acusaciones de solicitante contra Buendía, que comenzaron a circular en 1685 hasta llegar a diferentes dignatarios religiosos externos a la Compañía, ya fueran regulares o seculares ${ }^{102}$.

Al comienzo de los años de 1690, sin embargo, la situación del limeño se transformó. Si bien no coincidía con los criterios de su institución ni con los de sus pares, la consagración profana le abrió los círculos cortesanos del nuevo virrey Monclova. En la década anterior, su predecesor, Melchor de Navarra, había dejado poco espacio en la Corte para los predicadores locales al traer en su séquito a su propio orador, el jesuita Francisco López ${ }^{103}$. Impuesto por su patrón, López se había alzado rápidamente en el campo de la oratoria, sin suscitar no obstante un gran fervor entre el público capitalino ${ }^{104}$. La llegada de su sucesor sin orador titular trajo consigo pues un soplo de aire fresco a la Corte, del cual se benefició Buendía. Para el virrey entrante, la consagración urbana del jesuita era doblemente útil. Atraerse un orador celebrado por la ciudad

100 “judicium: mediocre, prudencia: mediocre”, Catálogo secreto de 1690, ARSI, Lima 6.

101 AHN, Inquisición, 1648, Exp. 20, f. 3v.

102 En 1685, unos mercedarios recogieron el testimonio de una feligresa, que se difundió entre la Inquisición, el exconfesor franciscano del virrey Castellar, el superior jesuita e incluso un dominico. AHN, Inquisición, 1648, Exp. 20, f. 3v-7v.

${ }^{103}$ Francisco López era hermano de otro criado importante de Navarra y Rocafull, Juan Luis López.

104 En 1684, López predicó por ejemplo el sermón de honras a los soldados de la Monarquía en la catedral y el de las encenias en la Capilla de Palacio. 
constituía a la vez una manifestación de poderío en general y una publicidad favorable en particular para un recién llegado.

Monclova empezó empleando al hombre de letras para varios sermones. En 1692 por ejemplo, Buendía pronunció a pedido suyo las honras a los soldados de la Monarquía, que inclusive fueron publicadas ${ }^{105}$. Luego, las relaciones entre ambos se profundizaron aún más y Monclova integró al jesuita a sus círculos de íntimos. Según los inquisidores, el jesuita mantuvo "gran inclusión [...] con el Virrey Conde de la Monclova quien [...] le mantuvo en esta ciudad, en la frecuente asistencia de su Palacio de día y de noche" ${ }^{106}$. Esta estrecha relación llevó Monclova, en 1701, a encargar a Buendía el relato de las ceremonias realizadas bajo su gobierno para la muerte de Carlos II, cuyo alcance era crucial debido a que todas las lealtades eran escrutadas en este periodo de inestabilidad política. Sobre todo, después de su fallecimiento el 22 de septiembre de 1705 , fue José de Buendía quien fue designado por el clan del virrey para pronunciar su elogio fúnebre ante la ciudad reunida ${ }^{107}$.

En tanto que eclesiástico regular, el favor virreinal supuso fundamentalmente para Buendía un elemento: el aumento exponencial de su poder informal. Para recompensar o retribuir a sus seguidores, Monclova disponía de un amplio repertorio de recursos de orden a la vez honorífico, laboral o económico. No obstante, aunque fuesen oportunos para un hombre de letras seglar como Pedro de Peralta y Barnuevo, eran inadecuados para el jesuita. El arsenal de honores o plazas que podían distribuir los virreyes se limitaba pues a las administraciones reales y a los cargos de Palacio. No alcanzaba a una institución como la Compañía, la cual poseía sus propias instancias de promoción. Sin embargo, si bien Monclova no podía intervenir directamente sobre la carrera de su protegido regular, le ofrecía en cambio un alto grado de poder informal. No solo Buendía obtuvo con su inscripción cortesana un conocimiento inédito de los asuntos gubernamentales, sino que también se benefició de una capacidad de intercesión directa ante el primer representante del monarca en el virreinato. De hecho, Buendía no dudó en usar a diferentes niveles este capital político oficioso. A

105 Según lo que afirma el propio Buendía, dirigiéndose a Monclova: “a mí me mandó predicar", Buendía, 1693, [f. 18r]. Desgraciadamente, las informaciones sobre las predicaciones de Buendía para esta fase de su trayectoria son escasas. Sabemos que, en octubre de 1702, predicó otro sermón para el virrey. Cf. Firbas, 2017, p. 189.

106 AHN, Inquisición, 1648, Exp. 20, f. 2r.

107 “Asistió de duelo toda su familia, hasta el sábado 3 de octubre, en que se hicieron las honras con el mesmo concurso de nobleza, religiones, colegios, universidad, Cabildos, tribunales y Real Audiencia. Cantó misa el señor deán y predicó el M. R. P. M. Joseph de Buendía, de la Compañía de Jesús", Firbas, 2017, op. cit., p. 350. 
nivel de su linaje, lo empleó a favor de ambiciones familiares, lo cual explica, en 1708, el casamiento tardío, aunque muy favorable de su hermano menor con la hija de Juan Soto y Vaca, caballero de Alcántara.

En base al incremento de su poder, la inscripción cortesana provocó, a partir de 1690, lo que la consagración urbana no había logrado: el ascenso de José de Buendía tanto en su Orden como en la intelectualidad limeña. Al parecer, la primera en reaccionar favorablemente fue la esfera erudita. Con su entrada en la Corte, el jesuita empezó a verse solicitado por diferentes autores para la aprobación de ciertas publicaciones. El procedimiento manifestaba entonces el grado de ascendente de los hombres de letras sobre sus pares por su valor de homologación intelectual. Hasta la muerte de su protector Monclova en 1705, Buendía llegó a ser, con cinco pareceres, el jesuita más requerido en Lima, por encima incluso de figuras como Nicolás de Olea y Diego de Egúluz ${ }^{108}$. En términos comparativos, si bien Aguilar rebasaba a Buendía en el organigrama de la Orden, ningún literato o autor se le acercó para solicitar su firma. El nivel de asentamiento institucional de Aguilar no poseía pues para la intelectualidad limeña el grado de atractividad y utilidad de la posición cortesana de Buendía. Asimismo, a nivel de la Provincia jesuita, la apreciación de los superiores del orador mejoró también considerablemente. Hacia 1696, su juicio, prudencia y experiencia fueron por primera vez considerados de manera positiva ${ }^{109}$. El mismo año, el jesuita fue nombrado cronista de la Provincia. Luego, durante la Congregación provincial de 1699, fue designado secretario ${ }^{110}$.

La protección virreinal hubiera podido llevar aún más lejos a Buendía. Sin embargo, a diferencia de otros, el hombre de letras tendió a gestionar mal el poder político oficioso que le ofreció su posición en la Corte. Dicho poder se prestaba a una diversidad de usos, de los cuales el más seguro para un hombre de letras era su conversión a un poder oficial. Por haber basado su trayectoria sobre la esfera profana más que sobre una progresión jerárquica interna, el jesuita se encontraba además bastante desprovisto de oficialidad. Pero en vez de obrar al fortalecimiento de su arraigo institucional en la Compañía, Buendía

${ }^{108}$ Entre 1690 y 1705, Olea y Eguíluz firmaron respectivamente cuatro aprobaciones. Olea falleció en 1705 y Eguíluz en 1704.

109 "juicio bueno, prudencia buena, experiencia bastante", catálogo secreto de 1696, ARSI, Lima 6.

110 Vargas Ugarte, 1963, op. cit., T. II, p. 311. Sobre el desempeño historiográfico de Buendía durante esta nueva fase de su trayectoria, véase Millar Carvacho, 2018, pp. 572-577. Para Millar, el estancamiento del proceso de beatificación de Francisco del Castillo se debió en parte a las modalidades de escritura del jesuita, que no concordaban con las nuevas expectativas de la Santa Sede. 
aplicó su poder informal, a partir de 1697, al conflicto interno en la Provincia. Al igual que Aguilar, el limeño formó parte del partido que se opuso al visitador. Ahora bien, cuando este terminó victorioso, no dudó, cuando le fue posible, en deshacerse de un adversario inoportuno, poco elevado en la jerarquía de la institución y cuya trayectoria se había construido sobre la apreciación informal de instancias externas.

José de Buendía se sirvió al menos dos veces de su influencia en Palacio para obstaculizar una de las vertientes del arsenal ofensivo del visitador: el traslado. Apenas llegado, Altamirano utilizó en efecto la estrategia de dispersar a sus adversarios, fundada sobre la amplitud de sus prerrogativas. En enero de 1698, desplazó al jefe del partido enemigo, Eguíluz, del colegio de San Pablo al del Cercado ${ }^{111}$. En 1701, no solo trató de mandar a Grijalva al Cuzco, sino también apartó de la capital a Nicolás de Torres ${ }^{112}$. Después, en 1701, maniobró para despedir a Martín de Morante de Lima. Precisamente, desde mediados de 1698, José de Buendía fue uno de los primeros blancos de esa política de neutralización de Altamirano. Por el mes de abril, el visitador intentó deshacerse del protegido del virrey, atribuyéndole por primera vez un cargo directivo: la prefectura de Estudios Mayores del Colegio de $\mathrm{Cusco}^{113}$. A pesar de ello, gracias a Monclova, Buendía trabó no obstante la decisión de su superior ${ }^{114}$. Logró la permanencia en Lima, aprovechando la ocasión para ostentar un cargo que nunca ocuparía. Luego, la segunda utilización por Buendía del poder de su protector se dio tres años después, durante el episodio de confrontación con la Inquisición. Unos días después de Eguíluz y de Aguilar, el 28 de abril de 1701, el jesuita se presentó también ante el Santo Oficio para tratar de impedir el despido de Grijalba ${ }^{115}$. Sobre todo, el hombre de letras apeló nuevamente a su patrón, quien se implicó fuertemente ${ }^{116}$.

111 En el correo oficial, el general Tirso González había atribuido a Eguíluz el prestigioso rectorado de San Pablo para el trienio de 1698, pero gracias a sus facultades, Altamirano pudo suspender la decisión romana. Vargas Ugarte, 1963, op. cit., T. II, p. 306.

112 AHN, Inquisición, 4786, Exp. 3, f. 2v.

${ }_{113}$ Buendía ostentó el título en abril de 1698 para una aprobación, que firmó no obstante en Lima.

114 Según los inquisidores: "el Virrey Conde de la Monclova quien contra la determinación de sus prelados le mantuvo en esta ciudad", AHN, Inquisición, 1648, Exp. 20, f. 2r.

115 "Por donde juzgo debo denunciar y denuncio a d[i]cho P. Visitador de injuriosso al Santo Tribunal", AHN, Inquisición, 4786, Exp. 3, f. 83r.

116 Buendía mencionó al virrey ante la Inquisición. Según él: "el gran jucio del s[eno]r Virrey, hablando de este punto, asegura que luego, que supo la defensa y vio el rectorado, infirió que este rectorado venia de esta defensa", AHN, Inquisición, 4786, Exp. 3, f. 82r. Según los inquisidores: 
Si bien sirvió a su partido, el uso por el hombre de letras de una influencia política externa e informal para un conflicto interno desgastó no obstante rápidamente su posición en la Orden. A diferencia de Aguilar, Buendía no se beneficiaba de una inscripción institucional suficiente como para respaldarlo. Al contrario, por haber fundado su trayectoria sobre la apreciación de instancias externas más que sobre la progresión jerárquica interna, constituía un blanco fácil para sus adversarios jesuitas. Cuando, para 1702, Altamirano consiguió retomar el control de la Provincia, el jesuita fue duramente castigado. Sus apreciaciones se degradaron y perdió su cargo de cronista para regresar a un simple puesto de operario ${ }^{117}$. Sobre todo, las nuevas autoridades provinciales empezaron a intentar dirigir en contra suya el poder inquisitorial. Se trataba pues de eliminar indirectamente a un adversario poderoso, pero falto de solidez institucional. Las presiones comenzaron probablemente hacia 1703. El 11 de abril, el limeño se presentó al Santo Oficio para autodenunciarse. Aunque lo negase, se trataba de anticipar alguna acusación y proporcionar a los inquisidores una autodefensa ${ }^{118}$. De hecho, los inquisidores se contentaron esa vez con archivar la denuncia, sin formular cargos.

La segunda tentativa de instrumentalizar la Inquisición ocurrió en 1708 y esta vez funcionó. A inicio de julio, el lugarteniente del visitador, Luis de Andrade, fue promovido a Provincial. El ariqueño había participado en todos los combates en contra del partido de Eguíluz y había sufrido directamente sus ataques. A los pocos días de su entronización al Provincialato, Andrade debió de negociar con los inquisidores la inculpación de Buendía ${ }^{119}$. En efecto, el 13 de julio de 1708, el Santo Oficio retomó finalmente su autodenuncia de 1703 para abrirle un proceso por solicitante. Sin embargo, los cargos en contra del hombre de letras eran relativamente reducidos. No solo Buendía no había reconocido más de cuatro relaciones, sino también algunos de los testigos que poseía por otra parte la Inquisición se habían retraído o habían muerto. A modo de comparación, cuando por 1693 los inquisidores habían decidido actuar en

\footnotetext{
"hasta el Señor Virrey lo entendía así", f. 8r. "avia de ser muy mal visto [la salida de Grijalba] al mismo tribunal, al Señor Virrey”, Ibid., f. 9r.

117 "jucio inquietu, prudencia exigua, experiencia nulla", Catálogo secreto de 1703, ARSI, Lima 6. Para 1706: "jucio mediocre, prudencia exigua". Para 1710: "juicio mediocre, prudencia ídem". Para 1716: "jucio exiguo, prudencia exigua, experiencia nulla".

118 AHN, Inquisición, 1648, Exp.20, f. 16r. Buendía presentó su autodenuncia leyendo un papel preparado antes, en el que se defendía teológicamente.

119 AHN, Inquisición, 1648, Exp. 20, f. 19v. Andrade regresó à Lima en julio de 1708 para ser oficialmente entronizado Provincial, el 14 de agosto. Saldamando, 1882, p. 363. Irónicamente, el propio Andrade tendría a su vez problemas con la Inquisición 15 años después. Cf. AHN, Inquisición, 1649, Exp. 46.
} 
contra de otro jesuita, Martín de Morante, por solicitante, este había reconocido hasta 27 relaciones. Los funcionarios del Santo Oficio se empeñaron pues en consolidar la acusación, por lo que indagaron en sus fondos. Un mes después, el 7 de agosto de 1708, añadieron al expediente de Buendía un testimonio de más de 20 años, procedente de otro proceso, llevado en torno a Ayllón. Recogida el 15 de febrero de 1689, se trataba de la declaración de una amiga de Ayllón, María del Rosario, quien acusaba al jesuita de haber utilizado la muerte del seglar para alimentar su celebridad urbana ${ }^{120}$.

Con esta adición tardía, los cargos que pesaban sobre Buendía eran ya más sólidos. Paradójicamente, fueron producto en cierta medida de su larga estrategia de adhesión a los sectores profanos. Por su origen, surgieron como una respuesta a su uso del capital político cortesano en contra del partido del visitador. Por su contenido, la acusación de María del Rosario procedió de su empeño por fidelizar al público urbano. Después de consultar la Suprema en Madrid, los inquisidores limeños ordenaron, el 16 de noviembre de 1711, el arresto de José de Buendía, quien fue sentenciado el 23 de marzo de 1712. Además de tener prohibido predicar durante dos años, fue condenado a la degradación de una penitencia pública en la iglesia de Santa Ana, a la que asistió mucha gente ${ }^{121}$. Luego, fue enviado en exilio primero a Huamanga y después a Cuzco, donde falleció el 26 de mayo de 1727. Tanto más impresionante cuanto que era grande, la caída del orador estrella se hizo posible por un elemento central de su trayectoria: la debilidad de su arraigo institucional.

A partir de sus inicios en la Orden, José de Buendía apostó por el favor urbano. No solo era más rápido en la concesión de sus gratificaciones que el reconocimiento de los pares, sino que también constituía una vía menos disputada en la Provincia peruana que la del cursus honorum tal como lo siguió Aguilar. Efectivamente, le procuró de manera precoz fama e influencia y, para 1690, Buendía reinaba sobre el campo de la elocuencia sagrada limeña. Pero, si bien era rápida y brillante, la consagración de los sectores profanos no tenía poder directo sobre la institución ignaciana y el otorgamiento de ascenso. Al contrario, pese a su éxito externo, el jesuita no progresó en el organigrama interno de la Orden ni tampoco en la intelectualidad capitalina. A partir de 1690, su integración a los círculos del virrey Monclova le permitió no obstante rebasar esa limitación. Buendía hubiera podido incluso contrarrestar la debilidad de su posición institucional gracias al abanico de recursos que le proporcionaba la protección virreinal. Desgraciadamente, en lugar de convertir su poder informal

120 AHN, Inquisición, 1648, Exp. 20, f. 24r.

121 Medina, 1887, op. cit., p. 99. 
en poder formal, Buendía empleó su capital político cortesano para intervenir en las luchas partidarias en su Orden. Del lado de los perdedores, no pudo luego apelar a ninguna oficialidad personal para protegerse de las represalias de los vencedores.

\section{Conclusión}

La diferencia entre los dos hombres de letras en la orientación de sus trayectorias se expresó incluso en sus relaciones con la autoría. Orientado hacia la esfera profana, José de Buendía asumió varias veces un anonimato literario. Su proceder era relativamente artificial, puesto que el jesuita dejaba luego filtrar en publicaciones posteriores su paternidad, pero le sirvió para suscribirse en Lima al régimen mundano de la relación con las letras, caracterizado por un desinterés ostentado por la propiedad intelectual ${ }^{122}$. José de Aguilar, quien construyó su trayectoria sobre los valores de su Orden, adhirió en cambio a otro régimen. No solo reivindicó sistemáticamente su autoría, sino también tuvo una verdadera ambición literaria que se manifestó en diferentes proyectos editoriales. Su muerte inesperada en 1708 le impidió llevar a cabo su último proyecto: la publicación de nuevos sermones. ¿Cuál fue el motor inicial de la diferencia de estrategias entre Buendía y Aguilar? Al menos dos elementos explicativos pueden mencionarse. A nivel social, los orígenes familiares de ambos jesuitas jugaron sin duda un papel significativo. A nivel individual, las fuentes muestran también a un Buendía seguro de sí mismo y que hipotéticamente pudo dejarse llevar por su excelencia oratoria y las ganancias de su celebridad precoz.

Este texto no pretende haberlo dicho todo sobre los dos hombres de letras. Numerosos aspectos de sus existencias han sido apenas aludidos, pese a su interés. Tales como se presentan, sus trayectorias nos informan no obstante sobre elementos de orden metodológico e historiográfico. En términos metodológicos, se trata de subrayar el interés que representa como herramienta el concepto de campo de la oratoria. Ofrece renovar las perspectivas de estudio de un corpus de fuentes primarias particularmente abundantes en el caso de la América virreinal: los sermones. Hasta ahora, se han prestado principalmente a análisis de orden literario, lo cual sigue indispensable. Sin embargo, este texto ambiciona subrayar su interés para la investigación como material para reconstituir el contexto laboral de la predicación, ya sea midiendo elevaciones

122 Sobre cultura escrita e impresa en el Antiguo Régimen, véase Bouza, 2016. 
y declives individuales (perspectiva cualitativa), o elaborando panoramas grupales (perspectiva cuantitativa).

En términos historiográficos, las trayectorias de los dos jesuitas instruyen sobre las instancias y mecanismos de promoción para los hombres de letras regulares en una de las dos cabeceras del Imperio hispánico en América a finales del siglo XVII. La figura de Aguilar ilustra el mecanismo de ascenso más legítimo, el cual se inscribía dentro del perímetro reservado de la institución jesuita. Compartido por toda la Compañía, descansaba primero sobre la enseñanza de la teología, la cual constituía el principal filtro de selección de las élites dirigentes ignacianas. Se complementaba luego con un avance gradual en la jerarquía de la institución, cuya cúspide era, en el virreinato, el rectorado del San Pablo y el Provincialato. Pero si bien ese cursus honorum era similar en todos los espacios jesuitas, la presión demográfica le dio no obstante un cariz singular en la Provincia peruana. Además del talento y otras consideraciones, los apoyos clientelistas tendieron a constituir requisitos previos indispensables para poder cursarlo. Por su parte, el caso de Buendía subraya la existencia de instancias alternas, externas al ámbito jesuita e incluso eclesiástico: la esfera urbana y la Corte. Más allá de su aparatosa caída causada por una coyuntura específica, el hombre de letras ignaciano no solo existió profesionalmente durante más de 30 años, de 1673 a 1705, sino que también se construyó gracias a ambas una verdadera autoridad que debió de extenderse incluso fuera de Lima. Si bien la Compañía proporcionaba a sus miembros cargos oficiales y prestigio institucional, las esferas profana y cortesana proporcionaban pues otros recursos y gratificaciones interesantes para los regulares. El espacio cortesano en particular ofrecía potencialmente poderosas herramientas para afianzarse en Lima, si eran bien manejadas. En ese sentido, este texto busca matizar las interpretaciones que ven no solo en la Corte virreinal, sino también en el público capitalino, instancias débiles o inoperantes para los hombres de letras y sus desarrollos.

\section{Bibliografia}

Aguilar, Fernando, Carta del Padre Fernando de Aguilar, de la Compañía de Jesús, Rector del Colegio Máximo de San Pablo de Lima para los superiores de las casas y colegios de esta Provincia del Perú, sobre la muerte y vida exemplar del Padre Diego Francisco Altamirano, sugeto, y visitador, que fue de esta misma provincia, [s.n.], [1716].

Aguilar, José, Sermones varios, predicados en la Ciudad de Lima, Corte de los Reynos del Perú, Bruselas, Francisco Tsertevens, 1684.

Sermones varios, Sevilla, Imp. Juan Francisco Blas, 1704.

Sermones del dulcissimo nombre de María, Sevilla, Imp. Juan Francisco Blas, 1704. 
Sermones varios de misión, Madrid, Imp. Viuda Matheo Blanco, 1716. 1722. Sermones varios, panegíricos morales, Madrid, Imp. Gabriel del Barrio, Sermones varios morales, Madrid, Imp. Gabriel del Barrio, 1723. Sermones varios, panegíricos morales, Madrid, Imp. Alonso Balvas, 1731.

Aguirre, Rodolfo, El mérito y la estrategia: clérigos, juristas y médicos en Nueva España, México, Unam, 2003.

Benito Rodríguez, José Antonio, “Organización y funcionamiento de los tribunales de la Cruzada en Indias”. Revista de Estudios Histórico-Jurídicos, ํ22, 2000, pp. 169-190.

Bouza, Fernando, Corre manuscrito: Una historia cultural del Siglo de Oro, Madrid, Marcial Pons, 2016.

[Buendía, José], Sudor y lágrimas de María Santísima en su santa imagen de la Misericordia, Lima, Imprenta Juan Quevedo, 1676.

Sermones varios, predicados en la ciudad de Lima del Reyno de Perú por un orador estimado, bien oido y aplaudido de los mejores ingenios de aquel reyno, Zaragoza, Herederos de Iuan de Ybar, 1678.

Buendía, José, Vida admirable y prodigiosas virtudes del venerable y apostólico $P$. Francisco del Castillo, Madrid, Antonio Román, 1693a.

Oración fúnebre en honras de los soldados españoles difuntos, Lima, Imprenta José de Contreras, 1693b.

Oración fúnebre, que a las honras del venerable padre fray Francisco Camacho: religoso de nuestro padre San Juan de Dios, Lima, Imprenta José de Contreras, 1701.

Coello de la Rosa, Alexandre, "De mestizos y criollos en la Compañía de Jesús (Perú, siglos XVI-XVII)", Revista de Indias, vol. 68, N²43, 2008, pp. 37-66.

"La oratoria sagrada en el Padre Jacinto Barrasa, SJ (1626-1704)", Revista Andina, N45, 2007, pp. 115-134.

De la Puente Brunke, José, "Los oidores en la sociedad limeña: notas para su estudio (siglo XVII)", Temas americanistas, N7, 1990.

Espinoza Rúa, Celes Alonso, "Un indio camino a los altares: santidad e influencia inquisitorial en el caso del "siervo de Dios" Nicolás de Ayllón”, Histórica, XXXVI.1, 2012, pp. 135-180.

Estenssoro Fuchs, Juan Carlos, Del paganismo a la santidad: La incorporación de los indios del Perú al catolicismo, 1532-1750, Lima, IFEA, 2003.

FECHNER, FABIAN, "Las tierras incógnitas de la administración jesuita: toma de decisión, gremios consultivos y evolución de normas", Histórica, XXXVIII (2), 2014, pp. 11-42.

Firbas, Paul; José Antonio Rodríguez Garrido, Diario de noticias sobresalientes (1700-1711), New York, IDEA/IGAS, T.I., 2017.

Fuentes, Manuel Atanasio, Estadística general de Lima, Lima, Tip. Nacional de M. N. Corpancho, 1858. 
Guibovich Pérez, Pedro, Censura, libros e inquisición en el Perú colonial, 1570-1754, Sevilla, CSIC, 2003.

Lohmann Villena, Guillermo, Los americanos en las ordenes nobiliarias, Madrid, CSIC, 1993.

Maldavsky, Aliocha, Vocaciones inciertas: misión y misioneros en la provincia jesuita del Perú en los siglos XVI y XVII, Sevilla, CSIC, 2012.

Medina, José Toribio, Historia del tribunal del Santo Oficio de la Inquisición de Lima, Santiago, Imprenta Gutenberg, 1887.

Millar Carvacho, René, "Configuración y reconfiguración de una imagen de santidad. Hagiografías sobre el jesuita limeño Francisco del Castillo (s. XVII-XX)", Hispania Sacra, vol. 70, N¹42, 2018, pp. 569-584.

Morales, Martín, “Las cartas de los jesuitas. Los pliegues de un género", Historia y grafia, $\mathrm{N}^{\circ} 43,2014$, pp. 51-76.

Mugaburu, José, Diario de Lima, Lima, Imprenta San Martí, 1917.

Diario de Lima (1640-1694) crónica de la época colonial, Lima, Sanmartí y ca., 1918.

Pastells, Pablo, Historia de la Compañía de Jesús en la provincia del Paraguay, Madrid, V. Suárez, 1912.

Rodríguez Garrido, José Antonio, "Espinosa Medrano, dramaturgo y colegial del Seminario de San Antonio Abad del Cuzco", en Carlos F. Cabanillas Cárdenas (ed.), Sujetos coloniales: escritura, identidad y negociación en Hispanoamérica (siglos XVI-XVIII), New York, IDEA, 2017, pp. 215-239.

SARtolo, Bernardo, Vida admirable y muerte prodigiosa de Nicolás de Ayllón, Madrid, Imprenta García Infaçon, 1684.

SuÁrez, Margarita, "Política imperial, presión fiscal y crisis política en el virreinato del Perú durante el gobierno del virrey conde de Castellar, 1674-1678”, Histórica, XXXIX (2), 2015, pp. 51-87.

Torres Saldamando, EnriQue, Los antiguos jesuitas del Perú: biografías y apuntes para su Historia, Lima, Imprenta Liberal, 1882.

URiarte, Eugenio, Catálogo razonado de obras anónimas y seudónimas de autores de la Compañia de Jesús pertenecientes á la antigua aistencia española, Madrid, Imprenta Sucesores de Rivadeneyra, T. II, 1905.

Vargas Machuca, Francisco, Oración panegírica al glorioso Apóstol S. Bartholomé Patrón del Hospital Real de Negros Horros enfermos, viejos e impedidos, Lima, Imp. José Contreras y Alvarado, 1694.

Vargas Ugarte, Rubén, La elocuencia sagrada en el Perú en los siglos XVII y XVIII, Lima, Academia Peruana, 1942.

Historia de la Compañia de Jesús en el Perú, Burgos, Imprenta Aldecoa, 1963.

Vida del siervo de Dios Nicolás Ayllón: o por otro nombre Nicolás de Dios, Buenos Aires, Imprenta López, 1960. 